\title{
Transformando lo local desde el medio ambiente: las políticas ambientales en las ciudades de Lyon, Francia, y Aguascalientes, México (1990-2002)
}

\section{Environmental impact upon urban areas: environmental policies in the cities of Lyon, France, and Aguascalientes, Mexico (1990-2002)}

Carlos Gil-García*

\begin{abstract}
This paper analyzes the urban environmental policies through two case studies: the urban community of Lyon, France, and the city of Aguascalientes, Mexico, over a twelve years period (1990-2002). The objective is to analyze the policy design and the policy implementation focusing on their effects on those two urban areas as well as public management and social participation in both cities. Evidence shows that key transformations are taken into account in both cases since the environment is viewed as a change catalyst taking experiences, ideas and policies from supranational organizations, and using them to position the cities as axes of integration and differentiation of environmental management.
\end{abstract}

Keywords: environment, cities, public policy, citizens, government, management, globalization.

\section{Resumen}

En este trabajo se presenta un análisis de políticas urbano-ambientales a través de dos estudios de caso: la comunidad urbana de Lyon, en Francia, y la ciudad de Aguascalientes, México, en un periodo de doce años (1990-2002). El objetivo es analizar el diseño y aplicación de políticas, así como sus principales efectos en el territorio urbano, en la gestión pública y en la participación ciudadana en ambas ciudades. Los estudios presentan elementos importantes de transformación centrados en el medio ambiente como detonador de cambio una vez que se toman experiencias, ideas y políticas de organismos supranacionales, enfocándolos a la necesidad de posicionar a las ciudades como ejes diferenciadores e integradores de gestión ambiental.

Palabras clave: medio ambiente, ciudades, política pública, ciudadanos, gobierno, gestión, globalización.

* Instituto Tecnológico y de Estudios Superiores de Monterrey, Campus Hidalgo, México. Correo-e: cgil@itesm.mx. 


\section{Introducción}

Las políticas urbano-ambientales tienen una mayor presencia en el desarrollo de las ciudades contemporáneas. En ellas se refleja un interés por entender la relación entre los individuos y su medio ambiente, y en particular por los efectos que ha dejado su actividad. El análisis de esta relación, si bien siempre ha existido implícitamente en la sociedad, se fortalece a finales de los años ochenta y principios de los noventa, al profundizarse las discusiones sobre el efecto negativo de la actividad humana en el medio ambiente. De ahí se desprende la necesidad de generar una acción pública que se enfoque de manera más determinante a las decisiones que conciernen a la relación sociedad-medio ambiente urbano. Una primera característica de esta discusión es su origen en agencias internacionales, vía la participación de actores con diferentes posiciones políticas y formación intelectual y académico-científica. La amplitud del debate sobre la degradación del medio ambiente ha promovido ideas, discursos, políticas y experiencias que han impulsado cambios en la actitud de los ciudadanos y en sus formas de participación.

De manera paralela a las transformaciones ambientales, la discusión sobre la función, capacidades y potenciales de los espacios locales como motores de transformación de su contexto ambiental ya tienen un lugar especial en la literatura. Los procesos descentralizadores se vuelven un recurso estratégico para la reactivación de lo local a escala global, el diseño de políticas públicas ambientales se vuelve un eje clave en la planeación de las ciudades (Borraz, 2000; Herrick, 1995; Hodos, 2002; Kettl, 2000; Pinson y Vione, 2000). En el caso mexicano las reformas constitucionales iniciadas en los años ochenta dan a los municipios nuevas facultades y competencias, mientras que en Francia la discusión acerca de la revitalización de lo local permite que surjan nuevas formas de asociacionismo, junto con la creación de agencias de coordinación centrales (Mabileau, 1993).

En este trabajo se analiza el proceso de políticas públicas urbanoambientales llevado a cabo en dos áreas: la comunidad urbana de Lyon (en adelante Courly), en Francia, y la ciudad de Aguascalientes, México, en un periodo de 12 años (1990-2002). Nuestra pregunta central se orientó en reconocer cómo y de qué manera el tema ambiental modificó el diseño de políticas ambientales en ambas ciudades, y a su vez conocer los efectos de las políticas urbano-ambientales tanto en la administración pública como en la participación social. A partir de una metodología de estudios de caso, analizamos las principales dinámicas en ambos espacios territoriales en el proceso de políticas públicas ambientales y sus princi- 
pales repercusiones en dos ejes: la gestión del medio ambiente y las transformaciones en los actores y en el territorio.

$\mathrm{Al}$ establecer este estudio en realidades contrastantes (una ciudad media mexicana y la segunda aglomeración urbana en importancia en Francia) logramos encontrar algunos patrones de similitud en el proceso de políticas ambientales, lo cual nos permitió inferir que ciertas dinámicas integradoras en su diseño y en la adopción de normas de gestión ambiental, o desde experiencias globales, se adaptaron y/o analizaron de forma muy similar en ambos casos. Del mismo modo, logramos detectar diferencias relevantes en las actitudes de los actores y en la participación ciudadana en cada caso, que hace referencia al contexto cultural y social de cada país, pero que también está cimentada de una u otra manera en la ola ambiental que inicio en los años noventa, la cual tuvo especial efecto en Europa. Finalmente, analizamos elementos de cambio en el espacio territorial, que en el caso de la Courly se enfocó en estrategias de internacionalización de la ciudad y, en el caso mexicano, en mecanismos de planificación urbana con enfoque ecológico. El trabajo se estructura en cuatro apartados: el primero presenta definiciones básicas en el análisis y diseño de políticas urbano-ambientales, el segundo desarrolla la metodología de los casos, en los tercero y cuarto se abordan los estudios de caso y por último se discuten las conclusiones principales.

\section{Definiciones básicas}

\subsection{Las politicas urbano-ambientales}

Éstas son políticas de organización y redistributivas. Políticas de organización ya que requieren, mediante la programación y planificación, generar un orden ambiental. Son redistributivas porque necesitan negociar y ajustar elementos entre dos temas contradictorios: el crecimiento económico y la preservación del medio ambiente. Además, el diseño de las políticas ambientales tiene un fuerte contenido transcodificador. Transcodificar es un término que se utiliza en informática y se entiende como el proceso mediante el cual una información se puede actualizar o convertir a un nuevo formato. El concepto, aplicado a las políticas ambientales, explica el reciclaje de prácticas ambientales realizadas en el pasado y que sirven de plataforma para las nuevas. La transcodificación es, en síntesis, un proceso de traducción de viejas prácticas a otras nuevas (Lascoumes, 1994). Corinne Larrue, por ejemplo, expone que el medio ambiente, como objeto de políticas públicas, se pone en marcha en diferentes niveles: "La noción de medio ambiente reenvía a un campo de la acción pública aprehensible a través de seis dimensiones, consideradas 
como constitutivas de ese campo, y a las cuales podemos asociar un objetivo en términos de intervención pública" (2000: 39). En cada una de esas dimensiones figura la totalidad de los temas que constituyen la gran parte de los temas ambientales contemporáneos:

1. "Ecológica, que se enfoca a la protección de sistemas de vida.

2. Contaminación, que se dirige a atenuar la contaminación producida por las actividades del hombre.

3. Seguridad, que busca reducir o eliminar los riesgos ligados al medio ambiente, como es el caso de las inundaciones o los riesgos nucleares, pero también los riesgos ligados a la actividad humana. ${ }^{1}$

4. Recursos naturales, que busca racionalizar su uso y preservación; es el caso del agua, los bosques, los océanos, etcétera.

5. Calidad de vida, donde la acción se orienta a la investigación de mejores condiciones de vida (en materia de salud, seguridad) compatibles con el desarrollo económico y del ambiente.

6. Estética, donde el objetivo es armonizar, y de hecho integrar al medio ambiente como parte de los espacios habitables y de la vida cotidiana de los individuos" (Larrue, 2000: 40).

En este sentido, la dificultad de la política pública orientada al medio ambiente radica en el enfoque de sus acciones. Éstas corresponden a una serie de ajustes entre las trayectorias de desarrollo económico de la ciudad y, desde otra visión, a los ajustes de sus trayectorias de protección ambiental (Caldwell, 1995; Cheremisinoff, 2001). A ello se suma la necesidad de proteger la calidad de vida de la población que está permanentemente afectada por los efectos negativos que genera el desarrollo económico (contaminación, inseguridad, presiones demográficas, sobreexplotación de recursos naturales, etc.). Es la combinación de estos elementos los que desembocan en la base regulatoria de las políticas ambientales (Lascoumes, 1994). A su vez, éstas necesitan un ajuste permanente entre los intereses de los grupos ya que "las políticas públicas, cualquiera que sea su naturaleza, tienen evidentemente efectos redistributivos sobre y entre los grupos sociales que requieren arbitraje sobre ellos" (Duran, 1999: 20).

\footnotetext{
${ }^{1}$ La dimensión seguridad también se utiliza para articular lo que llaman crisis ambientales, pero parece ser mal entendida. Imber afirma: "Caracterizar temas ambientales como crisis es tan simplista como mal comprendido. Crisis es una descripción apropiada para algunas catástrofes naturales o para algunos desastres impredecibles e inesperados que involucran responsabilidad humana, como son los eventos en Chernobyl en 1986 y los incendios en pozos en Kuwait en 1991. Sin embargo, una definición bien establecida de crisis y sus implicaciones para la toma de decisiones requiere que tres factores específicos estén presentes: uno concierne al nivel de amenaza, dos factores conciernen a la cuestión de tiempo [...] una verdadera crisis combina: un alto nivel de amenaza; un corto periodo de advertencia, y la necesidad de una rápida respuesta" (1994: 19).
} 
Sin embargo, la dificultad se encuentra cuando los retos ambientales, creados a partir de temporalidades diferentes, surgen al mismo tiempo en las arenas políticas. Como resultado, la acción pública se evidencia en asimetrías y cambios (Borraz, 1999; Duran, 1999; Muller y Surel, 1998). Es aquí donde observamos con mayor intensidad la acción pública, entendida como una actividad colectiva que implica a la actividad de gobierno pero también a la actividad de la sociedad (Cabrero, 2005). La acción pública marca la conducción y dirección de las políticas públicas como un continuo entre Estado y sociedad, todo ello a través de principios reguladores y de ordenamiento mediante una mayor interacción social, coordinación e interacción de los actores. La mejor manera de entender la acción pública es por medio de la metáfora que propone Cabrero: es un vehículo de doble motor que, para tomar un impulso coordinado y regulado, necesita que tanto el Estado como la sociedad enciendan su actividad al mismo tiempo.

El análisis de políticas ambientales atestigua cómo las ciudades, con base en sus competencias, tamaño, población y recursos constantemente son confrontadas a arenas de políticas ambientales nacionales y arenas ambientales supranacionales que deben igualmente ser adaptadas e implantadas en su territorio. Este tipo de acciones genera espacios de incertidumbre y asimetrías puesto que actores y organizaciones requieren establecer patrones de organización para implantar políticas de diverso orden y origen (Dolowitz y Marsh, 2000).

Las políticas urbano-ambientales constituyen un buen ejemplo de estas asimetrías. Los nuevos temas ambientales se han sumado a la noción de desarrollo sostenible que Lascoumes y Le Bourhis (1997) consideran un tema híbrido, ya que se compone de conceptos difícilmente conciliables, como la protección del medio ambiente y el desarrollo económico. Estos temas se encuentran en las agendas sociales, económicas y de gobierno, pero de forma predominante gran parte de la discusión, el análisis, diseño y propuestas sobre el tema ambiental se construye y desarrolla en la escala supranacional, combinando la participación de numerosos actores (Corwell et al., 2005; Arnaud et al., 2005). Todo ello obliga a los actores locales a ajustar los objetivos de sus políticas, al tiempo que buscan conducir en el discurso y en los hechos una acción pública de conjunto que considere al ambiente como parte integral del desarrollo urbano-económico. Esta situación es más evidente en el ámbito europeo: en 1994 la Agencia Ambiental Europa afirmaba que dicho continente "tenía la necesidad de una planificación (ambiental) caracterizada por un enfoque de conjunto, integrado y de largo plazo" (CE, 1994: 27).

En el cuadro 1 se sintetizan los principales ejes de las políticas públicas ambientales. Se describe su diseño mediante la construcción del tema 
ambiental, la formulación de la política, el tipo de política que se piensa aplicar y, finalmente, los instrumentos de que se dispone para fortalecerla.

\subsection{Los instrumentos de las políticas públicas}

Las políticas ambientales requieren a la vez del desarrollo de numerosos instrumentos para su implantación. Estos organizan y movilizan el terreno en el que los actores participan o no, en correspondencia con la problemática ambiental, y también presentan las condiciones de una acción precisa (las leyes, el presupuesto, el sector ambiental que es afectado, las características de la intervención). Larrue (2000) distingue cuatro familias de instrumentos de políticas económicas incitativas. En el cuadro 2 se sintetizan los instrumentos.

Autores como Linder y Peters (1993) argumentan que quienes toman las decisiones o los diseñadores de políticas seleccionan los instrumentos a partir de sus planos cognitivos o desde la experiencia que adquieren con el uso de algún instrumento específico. Los instrumentos entre más sencillos son menos coercitivos, y los instrumentos menos coercitivos son más difíciles de controlar. Por otra parte, en los atributos de los instrumentos, quienes toman las decisiones hacen cálculos sobre los costos políticos que pudiesen tener. Éstos son desarrollados en función de su visibilidad y coerción. Cuando quienes toman las decisiones se enfrentan a situaciones donde las variables para seleccionar un instrumento permanecen sin cambio, tienden a elegir instrumentos que van del menos al más coercitivo. Linder y Peters (1993) nos recuerdan que en las organizaciones existen grupos de edad que determinan la selección de un instrumento a partir del tiempo que lleven dentro de la organización y de la percepción que tengan acerca de cómo solucionar los problemas. Por otra parte, y más importante aún que los grupos de edad, en las organizaciones encontramos la experiencia profesional que inclina a los individuos a seleccionar instrumentos a partir de ella. Por ejemplo, un economista preferiría hacer uso de la inferencia estadística para crear alternativas de solución a los problemas, pero utiliza la estadística no por su efectividad en la resolución de problemas sino por la utilidad del instrumento por sí mismo.

La búsqueda de un mejor instrumento es complicada ya que generalmente se tiende a combinar o a producir intercambios entre los instrumentos. Estos cambios implican que: 1) a mayor precisión del instrumento, menor probabilidad de que sea intrusivo; 2) a menor intrusión del instrumento, menos probabilidad de oposición pública, y 3) a mayor precisión del instrumento, más compleja y costosa es su administración. 


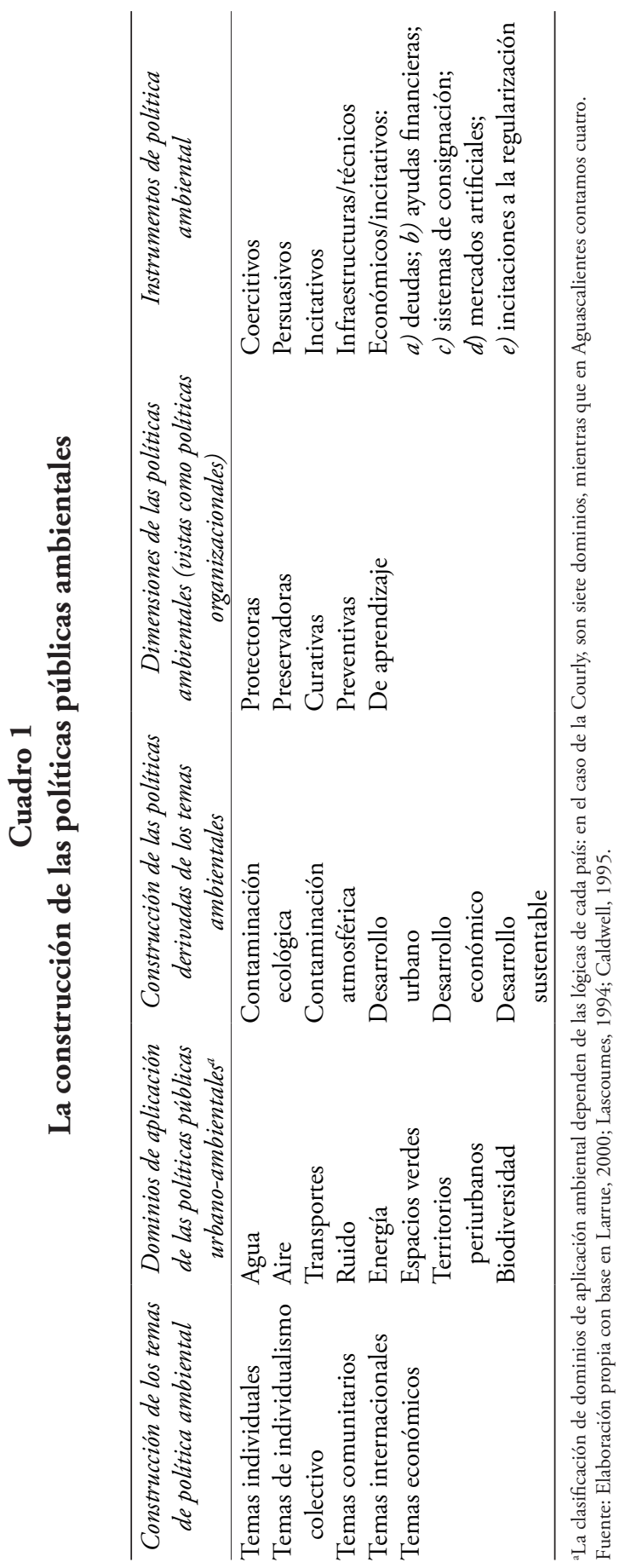




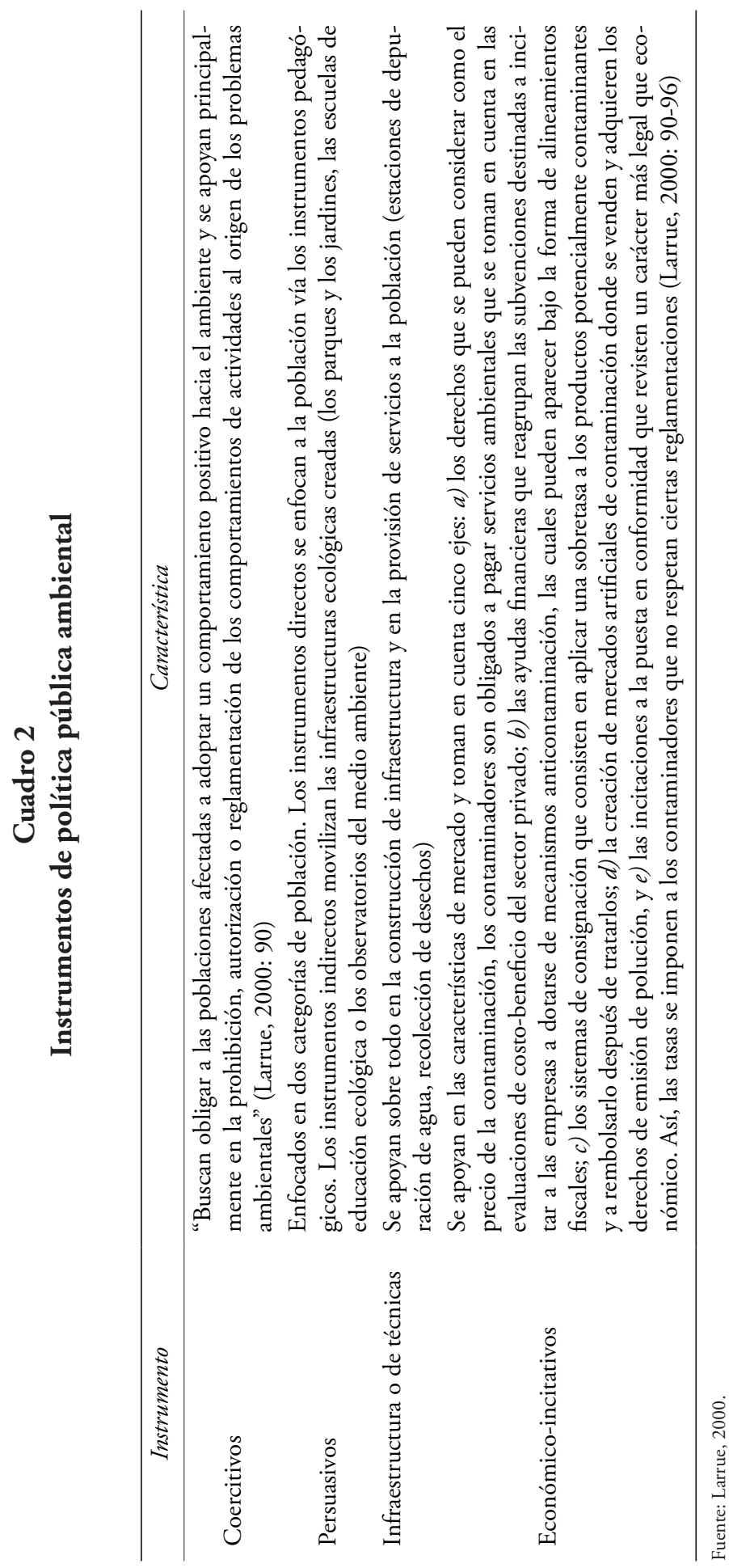




\subsection{Medio ambiente: identidad y espacio}

La categoría medio ambiente adquiere una relación clave a través de la construcción de identidad que los individuos profesan desde su espacio urbano territorial y sus interacciones con él. Las personas aplican diferentes valores omnicomprensivos a la categoría medioambiental y a las prioridades en las que colocan al medio ambiente como parte de su vida cotidiana, esto es, desde el contexto en el que se desenvuelven, la simbología que interpretan, los valores y cultura que comparten con un espacio urbano territorial específico y la relación que llevan en él. ${ }^{2}$ Algunos autores (Corral, 2002) van más allá de la búsqueda de la identidad como productora de acción colectiva proambiental. Con el argumento de que los procesos de construcción de identidad del ciudadano con su entorno son procesos no automáticos y en ocasiones ambiguos, es necesario contar con ciudadanos competentes (instruidos) en labores proambientales. Se destacan así las atribuciones que tienen los individuos: habilidad y motivación para participar en actividades proambientales. Sumados a estos dos requisitos es necesario contar con un tercero, que de cierta forma detona tales habilidades: una exigencia o requerimiento ambiental en el cual es necesario actuar. Sin este tercer factor, las habilidades y motivaciones proambientales de las personas se tornan en simples destrezas latentes.

\subsection{Medio ambiente y percepción de la acción pública}

Se asume que toda acción pública requiere un proceso de retroalimentación sobre sus resultados para que así se pueda reconsiderar y mejorar. La tarea de analizar los resultados de la acción de gobierno se realiza, en general, a través de indicadores de desempeño y procedimientos que evalúan el cumplimiento de objetivos y metas de una política. En síntesis, la acción de gobierno se recupera mediante sus resultados, desplazando la mayor parte del tiempo los efectos de sus acciones sobre los problemas

\footnotetext{
${ }^{2}$ Trabajos como el de Aguilar (2002) analiza los procesos de construcción de identidad en dos municipios mexicanos; Jiménez y López (2002) exploran la relación entre identidad y sustentabilidad en dos barrios de la ciudad de Guadalajara, en el estado de Jalisco, y Corral (2002) explora la creación de un modelo de competencia proambiental en dos ciudades del estado de Sonora, en México. Todos estos estudios exploran los diferentes procesos de construcción de identidades locales y la relación que éstas tienen con respecto a la acción colectiva relacionada con la protección del medio ambiente. Por otra parte, Kahn y Lourenço (2002) realizaron un estudio donde preguntaron a nińos de entre 10 y 14 ańos de tres ciudades y países diferentes (Houston, Estados Unidos; Lisboa, Portugal, y la Amazonia brasileńa) las consecuencias morales del deterioro ambiental, y encontraron semejanzas en las respuestas, así como una sorprendente tendencia de los niños a juzgar e involucrarse en cuestiones de protección del medio ambiente.
} 
que intenta resolver, en la organización social en la cual se sostiene y sobre el territorio en el cual está siendo implantada.

En el caso de la percepción de las políticas por parte de sus receptores inmediatos, contamos con una enorme fuente de inconsistencia en su desarrollo. Marie (1999) explica que la percepción que el ciudadano tiene de las políticas atraviesa por una serie de escalas:

1. La predisposición: el ciudadano percibe una política desde la perspectiva que tiene de su gobierno. El ciudadano puede simplemente no percibir la política o no enterarse de ella porque desconfía del servidor público o porque considera que al gobierno no le importa su bienestar personal.

2. La percepción estrecha o precisa: toda la acción de gobierno se percibe sólo en aquello que realmente le interesa al ciudadano, dejando a un lado potenciales beneficios colaterales de una política.

3. La forma temporal: el ciudadano evalúa la calidad de la política sólo cuando utiliza un servicio. Un ciudadano difícilmente se interesa por la estructura de una política o si su diseño tiene o no un sentido específico. Su tiempo y sus actividades se lo impiden.

\subsection{Las actitudes proambientales del ciudadano}

Se clasifican desde diferentes elementos: el militante, el científico, el social y el político. Todos ellos dependen en diferente grado del tipo de compromiso y alcance de la actividad que desarrollan. No sólo obedecen en la medida en que el ciudadano movilice su participación, sino que importan sobremanera las habilidades y aptitudes con que cuenta para poder activarla. El activismo ambiental tiene su origen en la idea de participación democrática y en el derecho a opinar e intervenir en aquellos proyectos que afectarán de forma permanente el ambiente urbano comunitario (Sainteny, 1998). Sin embargo, la participación de los actores sociales puede adoptar salidas positivas o negativas. Una gran parte puede optar por automarginarse o marginar a aquellos que tienen en sus manos la toma de decisiones, a fin de mostrar su oposición a un programa o proyecto ambiental. Como afirma Lascoumes (1994), existe un doble cuestionamiento de las asociaciones ambientales: una que discute su exclusión de los procesos de planificación, y otra que cuestiona los contenidos de la planificación.

Las interpretaciones de los actores involucrados en el proceso de toma de decisiones con carácter ambiental o desde sus percepciones sobre el medio ambiente, son ambiguas. Un ejemplo de ello son las respuestas de los individuos ante el deterioro ambiental, si por un lado están conscien- 
tes de la degradación ambiental, por el otro, las soluciones para evitar un daño más profundo requieren cancelar ciertos patrones de vida o conductas a los que están acostumbrados, situación que les genera dilemas morales. Por su parte, las actitudes de los actores políticos en la resolución de conflictos ambientales a partir de una visión de costo-beneficio toman en cuenta que "el crecimiento económico en lugar de ser percibido como un beneficio que mitiga los costos del daño ambiental, es observado como un costo en sí mismo, a su vez responsable de otro costo (la degradación ambiental) [...] el crecimiento económico como enfoque de política pública puede crear tensiones que generen conflictos, deteriorando un espacio mucho más gravemente de lo que se hubiese deteriorado en ausencia de tal crecimiento" (Gunderson, 1993: 114). Un ejemplo lo representan los dilemas para quien toma las decisiones al permitir que una industria generadora de empleos en el corto plazo contamine, pero que se confronta a los efectos en la salud pública en el largo plazo.

La conducta ambiental de los actores se desarrolla en tres perfiles: el primero es a través de élites conservadoras, que parecen manejar una imagen de naturalismo social proteccionista o de convivencia, y en cierto modo educativo, que sin embargo automargina los grandes problemas ambientales, dejando su resolución a las autoridades. Aquí, el medio ambiente (o naturalismo) sigue siendo una actividad que se entiende como ordenada y donde la naturaleza en sí misma se observa como peligrosa si no tiene orden (Melé, 2001). A partir de esta conducta, la participación social se activa mediante una serie de incentivos variados y difícilmente aislables para su análisis: la mayor parte del tiempo, la participación organizada y de largo alcance está motivada por intereses personales o por simpatía hacia tales actividades. Es el caso de los grupos ambientalistas que participan en la protección de fauna y flora. Otro tipo de movilización tiende más a contestar y a rechazar potenciales acciones o políticas en las que se verán afectados sus intereses o su calidad de vida (es el caso de los fenómenos Not in my backyard, NIMBY), en los que el rechazo a un proyecto es objeto de una fuerte atención y de una gran movilización.

Ciertos debates establecen que en el terreno de la participación social subyace la idea de una recuperación de espacios de democracia social y de coconstrucción y conducción de la acción pública (en especial el que se relaciona con procesos de toma de decisiones), dando por hecho que los ciudadanos requieren incentivos concretos para participar (Font, 2001; Epstein, 2000; Stewart, 2001). La pregunta sobre la capacidad ciudadana para participar en la aplicación de políticas públicas se ha debatido ampliamente. En el caso del medio ambiente, esta capacidad remite a una idea que combina habilidades y voluntad. 
El segundo perfil es el ambientalismo científico o político, apoyado en el conocimiento experto y en datos duros para incluir temas en la agenda política. Algunos trabajos (Leff, 1990; Barker y Peters, 1993; Falque, 1992) abordan el tema de la movilización medioambiental como una combinación entre militancia reivindicativa y militancia científica, en la que esta última sugiere la intervención de diferentes actores e incentivos, notablemente políticos y económicos, que colocan en juego ejes del desarrollo económico de un país. La ciencia, en efecto, es un eje clave para todo gobierno. En el caso del medio ambiente, las naciones deciden adherirse o no a tratados internacionales para su protección con base en la información de los comités científicos. La controversia se profundiza cuando mucha de la información científica la dirige o financia el Estado, y en la que por tanto existe un interés concreto (un interés político específico, dicho de otra forma) que en ocasiones se enfrenta a los de la militancia ambiental no científica. Por otra parte, este mecanismo se puede utilizar a la inversa. La militancia ambiental no científica hace uso del discurso científico, o de los propios científicos, para abanderar causas ambientales o marginar alguna posición oficial. La combinación de ciencia, política y medio ambiente es uno de los muchos dilemas que ha tenido que enfrentar el movimiento ambiental. A ello se debe agregar la tendencia a crear diferentes programas y acciones que giran sobre un mismo tema y que ponen en marcha diferentes agencias al mismo tiempo. Es interesante observar cómo los programas y las acciones son cada vez más determinadas por su contenido técnico (Besse, 2000). De esta forma, el ciudadano sólo puede apreciar una mínima parte del verdadero objetivo y sentido de un programa, así, éste no es lo suficientemente concreto para establecer su participación (Uzell y Pol, 2002).

Finalmente, el ambientalismo militante se enfoca a reivindicar demandas ambientales específicas (lo nuclear, OGM) y cuya organización tiene un origen internacional (Greenpeace o WWF), del cual atraen buena parte de su información y actividades. Estas organizaciones evidencian y confrontan los errores de la mundialización; ganan legitimidad por su capacidad para intervenir en el debate público y a través de la movilización de sus militantes; $y$ de igual forma pueden funcionar como organizaciones de vigilancia e información y fundan su legitimidad a partir de la independencia y la calidad de sus sistemas de información. Por último, generalmente son organizaciones de terreno y de cooperación, ya que asocian la voluntad de intervenir en los canales de comunicación que la globalización propone y desde los compromisos que de ella emanan. Autores como LeRoux (2007) y Brown et al. (2008) afirman que las ONG pueden ser vistas como una suerte de voz pública, ya que es posible que funjan como elementos de una nueva plataforma para reestructurar procesos de 
política local y de las agendas locales. Por su carácter social, sirven de manera importante como alternativas a las instituciones nacidas en el seno del mercado o del Estado. También pueden ser promotoras de formación de identidades y es posible que fomenten la creación de comunidades de intereses y que promuevan la actividad cívica y la formación de ciudadanos. $\mathrm{Al}$ nacer fuera del Estado y del mercado, las ONG sociales tienden a tener otro tipo de elementos. Se encargan de forma más adecuada de la misión y se sustentan en el trabajo voluntario, con una mayor adherencia a la misión, flexibilidad e innovación cuando se enfocan en los problemas sociales y de manera importante tienen mayor capacidad de satisfacer preferencias minoritarias.

\section{Metodología}

\subsection{Estudios de caso}

Los estudios de caso se seleccionaron de forma aleatoria. Su diseño fue de tipo intensivo-cualitativo y se buscó describir las principales características de las políticas, así como las consecuencias al final del periodo en el espacio social y de gestión de las ciudades (Yin, 1994; Arellano, 2006). De Aguascalientes ya se contaba con información previa debido a su carácter de ciudad piloto, donde la federación implementaba proyectos o programas que posteriormente se extendían al resto de ciudades mexicanas (Martínez, 1994). La comunidad urbana de Lyon se seleccionó inicialmente para conocer la dinámica del sistema local francés (Mabileau, 1993), pero terminó siendo el estudio de caso por las características de la región y en particular por su dinámica en las políticas urbano-ambientales.

El periodo de estudio se determinó de 1990 a 2002. Se realizaron visitas a ambas ciudades entre 2001 y 2002. En cada una se estableció una estrategia de recuperación de información de fuentes primarias, realizando entrevistas entre actores de agencias encargadas de la gestión ambiental o del diseño y aplicación de políticas ambientales; también se entrevistó a miembros de grupos ambientalistas. Las fuentes secundarias nos llevaron a recopilar planes, programas y proyectos enfocados a acciones de gobierno en materia ambiental.

\subsection{Variables}

Se seleccionaron tres variables de estudio: políticas públicas, gestión de la ciudad en el terreno ambiental y desempeño de los actores. La política pública se integró con los componentes de diseño (construcción de problemas, instrumentos, implantación y evaluación). La gestión ambiental 


\section{Cuadro 3 \\ Variaciones de contexto por caso}

\begin{tabular}{lrr}
\hline & Ciudad de Aguascalientes & Comunidad urbana de Lyon \\
\hline Composición & 8 comunidades & 57 comunidades \\
Extensión $\left(\mathrm{km}^{2}\right)$ & 224 & 515 \\
Población ciudad capital & 766,312 & 465,300 \\
$\begin{array}{l}\text { Población región } \\
\text { (millones) }\end{array}$ & 1 & 2.9 \\
Número de ejecutivos & & 2 \\
$\quad$ durante el periodo & 4 & \\
$\quad$ estudiado & & \\
Gobierno & Ayuntamiento & Consejo de la comunidad \\
$\begin{array}{l}\text { Duración de mandato } \\
\text { del Ejecutivo local }\end{array}$ & 3 años sin derecho a & 6 años con derecho a \\
Dinámica del sistema & reelección inmediata & reeleción inmediata \\
político & Federación & Estado central \\
\hline
\end{tabular}

Fuente: Elaboración propia.

de la ciudad en cada caso se estableció con los criterios de presencia de programas de políticas públicas, como es el caso de planes o proyectos enfocados al medio ambiente. El desempeño de los actores se determinó por el origen de la participación proambiental, esto es, por sus características de convivencia proteccionista, militante, o político/científica, y la incidencia de su participación en los procesos de toma de decisiones en el terreno ambiental. Finalmente, se seleccionaron algunos criterios clave de ambos sistemas, como las condiciones de territorio, población y organización política. En el cuadro 3 se muestran las variaciones políticas, demográficas y territoriales para cada caso.

\section{Comunidad urbana de Lyon}

\subsection{Diseño de políticas públicas en la Courly}

La problemática ambiental expuesta en los diferentes foros internacionales en los años noventa colocó rápidamente el tema ambiental en las agendas gubernamentales. Para la Courly, este proceso de discusión se insertó en un proyecto mayor: posicionar a Lyon como una Eurociudad (Bonneville, 1997). El deseo de globalizarla fue uno de los motivos centrales para iniciar la reestructuración de la aglomeración lyonesa, uno de cuyos ejes estratégicos era el medio ambiente. Los dos presidentes de la comunidad urbana, Michel Noir y después Raymond Barre, supieron articular estratégicamente el discurso del desarrollo urbano con la gran capacidad de gestión ur- 
bana existente. Ello llevó a elaborar las Cartas Ecológicas de la Ciudad y el Plan Azul (enfocado a la gestión del agua), y en la entrada del año 2000, con los programas Milenio 3, todos fueron fuertemente apoyados por los gobiernos integrantes de la aglomeración (Barraqué y Theys, 1998; Jouve, 1998).

La lógica de la acción pública urbano-ambiental muestra que su diseño, en un primer momento, dependió del alineamiento al discurso y visión del presidente de la aglomeración urbana y de la buena circulación de las ideas entre todos los miembros de la comunidad. Ello permitió anclar una voluntad política fuerte, con un marcado enfoque en la idea de la comunidad y en la combinación de las ambiciones internacionalistas de la ciudad. Los presidentes de la comunidad establecieron el llamado Consenso a la Lyonesa, cuyos objetivos eran construir una coalición enfocada a crear una dirección e identidad de comunidad en la aglomeración. Estos procesos también permitieron que los trabajos de construcción de la acción pública fueran más fáciles de introducir en la agenda. La agenda ambiental en esta ciudad se realiza de manera integral, esto es, se busca cubrir un mayor número de problemas de forma ampliada.

El medio ambiente fue muy favorecido por la voluntad de los funcionarios elegidos, acompañado de una fuerte presencia inicial de los miembros del Partido Verde, cuyos debates lo consideran un eje fundamental del futuro de la aglomeración. Esta acción ambiental, sostenida a partir de coaliciones más o menos estables entre los actores (en la construcción de la agenda, la negociación de las políticas, la conducción de la acción pública, el seguimiento y evaluación) fueron determinantes para el seguimiento de acciones ambientales. Es importante remarcar la dinámica militante del Partido Verde Francés, producto de la reivindicación del ambientalismo y las causas sociales que representaron en los años noventa una gran movilización de ciudadanos en Europa, lo cual promovió la inclusión de temas ambientales y sociales. Por su parte, las organizaciones ecologistas son aún más radicales y funcionan como organizaciones ciudadanas de confrontación (Arnaud et al., 2005).

La programación de la política ambiental se realizó mediante las Cartas Ecológicas de primera (1992-1995) y segunda generación (1997-2002) (Charte de l'Écologie Urbaine du Grand Lyon, 1992; Charte de l'Écologie Urbaine, Agenda 21, 2000a, b). Dichos documentos concentran las principales metas, objetivos y estrategias de planificación de la comunidad enfocadas a temas ambientales. Estas cartas las diseñaron las agencias de urbanismo y de medio ambiente. Además, la Carta Ecológica 1997-2002 se implementa como la primer Agenda 21 local en la ciudad. En ella también se integran los nuevos sistemas de gestión ambiental, como el iso 14000 y sus derivados (Écologie Urbaine, 1996). Estas certificaciones se aplicaron en los procesos de rellenos sanitarios y en el corredor industrial 
de Lyon. Estos procesos se vinculan con las políticas ambientales como parte de la estrategia de la ciudad para posicionarse en el plano global. En esta agenda también se evoca la implantación de mejoras en la estaciones de tratamiento de agua para obtener la norma internacional Iso 14000, por un lado, y la Iso 14001 relativas a la gestión ambiental de los desechos, por el otro. Estas certificaciones se obtuvieron en 2003 y de entonces a ahora se han extendido a certificaciones de sistemas de gestión y mantenimiento en los rubros de tratamiento de aguas y desechos sólidos.

Por otro lado, los representantes de la aglomeración hicieron un uso adecuado de los nuevos mecanismos y facultades que la descentralización otorgó a los gobiernos locales en Francia. El hecho de contar con agencias ambientales propias, que impulsan la planificación de la comunidad, les representó un importante logro. De este modo, se observó como negativa la existencia y aplicación unilateral de las cartas ecológicas (diseñadas y aplicadas desde la comunidad urbana), ello habla también de la capacidad de la comunidad para movilizar recursos y personal. Esto no habría sido posible sin la participación activa y el deseo de los presidentes de la comunidad para integrar sus ideales de ciudad en las áreas de programación y planificación y, posterior a ello, saberlas articular entre los diferentes actores y grupos al interior de la comunidad. Además, los años 1990 a 1992 quedan como el periodo de mayor movilidad y discusión alrededor del tema, ya sea en el ámbito nacional con la formación de las Direcciones Regionales del Medio Ambiente (Diren), o internacional, donde el ambiente evoluciona como una variable estratégica del desarrollo de la ciudad. Los costos de este consenso y regulación fue el aumento en el número y presencia de los actores ambientales, que posteriormente bloquearían algunos procesos de planificación urbana.

\subsection{Efecto de las políticas urbano-ambientales en la gestión de la ciudad de Lyon}

La política ambiental en Lyon evidencia situaciones particulares: 1) el peso de la ciudad central en la configuración de la acción pública y el tipo de gestión de servicios de la comunidad hablan de su liderazgo en relación con las comunidades vecinas, la cual marca el ritmo de la acción pública utilizando consensos entre las comunidades que la conforman, a fin de activar las políticas generales y las políticas ambientales en lo particular; 2) los registros institucionales remiten a un diseño específico del desarrollo de Lyon: su característica de cluster por comunidad, que combina un espacio fragmentado del que se desprende una coordinación y gestión en tres niveles: a) la coordinación administrativa interna, $b$ ) el control político de transferencia de poder a la intercomunalidad, y $c$ ) la regulación de las actividades delegadas a la intercomunalidad. 


\section{Cuadro 4}

Carta Ecológica Urbana del Gran Lyon, 1992-1995 y 1997-2001

\begin{tabular}{|c|c|c|}
\hline Dominio & Acciones & $\begin{array}{c}\text { Evaluación } \\
1996\end{array}$ \\
\hline Energía & $\begin{array}{l}\text { Generación de energía menos contaminante; hallar } \\
\text { productos menos contaminantes; producción de } \\
\text { alternativas de transporte; búsqueda de asociaciones } \\
\text { públicas y privadas; disminuir los efectos de las in- } \\
\text { dustrias contaminantes; informar a la población }\end{array}$ & $100 \%$ \\
\hline Agua & $\begin{array}{l}\text { Proteger los campos de captación de Crémieux- } \\
\text { Charmy; asegurar los apoyos de estiaje vía la creación } \\
\text { de cuencas de ventilación; asegurar un mejor trata- } \\
\text { miento del agua del lago Miribel en caso de auxilio } \\
\text { gracias a la construcción de un decantador de la } \\
\text { fábrica de seguridad de la Pape; hacer fiable la red } \\
\text { con una gestión automática; prohibir la entrada de } \\
\text { agua exterior en la red; proteger y asegurar las fuen- } \\
\text { tes de agua potable; completar la red de colecta de } \\
\text { aguas usadas y pluviales; actuar por una depuración } \\
\text { más completa; preservar el medio natural por una } \\
\text { buena calidad del agua tratada antes de ser desecha- } \\
\text { da; campańa de sensibilización e información para } \\
\text { un uso racional de la red de agua; el Plan Bleu; va- } \\
\text { lorización de las orillas y de los espacios acuáticos } \\
\text { naturales }\end{array}$ & $80 \%$ \\
\hline Desechos & $\begin{array}{l}\text { Organizar una mejor colecta; aumentar las capaci- } \\
\text { dades de tratamiento; desarrollo de nuevas filiares } \\
\text { de compostaje y reciclaje; búsqueda de un nuevo } \\
\text { centro de relleno sanitario técnico; información de } \\
\text { funcionarios y usuarios }\end{array}$ & $88 \%$ \\
\hline Aire & $\begin{array}{l}\text { Reforzamiento de medios de control (por extensión } \\
\text { del número de captadores y parámetros de medi- } \\
\text { ción); reducción de emisiones industriales y domés- } \\
\text { ticas; disminución de emisiones producto de la } \\
\text { circulación de vehículos; información de usuarios y } \\
\text { controles anticontaminación }\end{array}$ & $90 \%$ \\
\hline Riesgos & $\begin{array}{l}\text { Conocimiento de riesgos (mapas de riesgo de mo- } \\
\text { vimientos de tierra; ayudas a la decisión (recursos } \\
\text { cartográficos); riesgos tecnológicos; desarrollo de } \\
\text { técnicas de fabricación menos contaminantes; con- } \\
\text { trol de localización de sitios; recalificación de espa- } \\
\text { cios; plan de circulación de material peligroso; } \\
\text { campaña de sensibilización e información }\end{array}$ & $75 \%$ \\
\hline
\end{tabular}


Cotinúa Cuadro $4 .$.

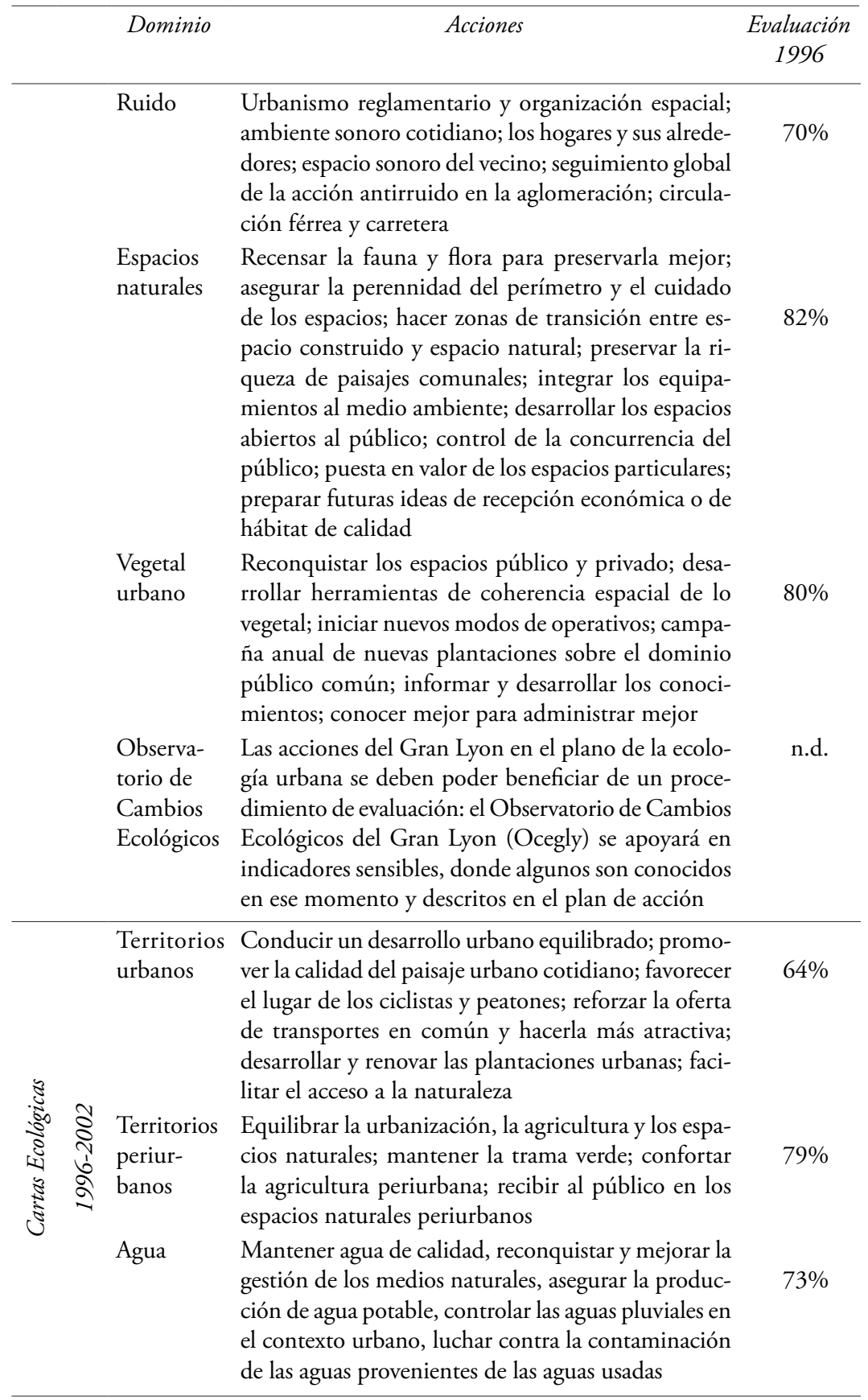


Cotinúa Cuadro 4...

\begin{tabular}{|c|c|c|}
\hline Dominio & Acciones & $\begin{array}{c}\text { Evaluación } \\
1996\end{array}$ \\
\hline Desechos & $\begin{array}{l}\text { Dirigirse a una gestión óptima de los desechos, } \\
\text { promover los aportes voluntarios; desarrollar la co- } \\
\text { lecta selectiva de desechos, mejorar los equipamien- } \\
\text { tos y los tratamientos; controlar el futuro de los } \\
\text { desechos }\end{array}$ & $51 \%$ \\
\hline Aire & $\begin{array}{l}\text { Mejorar la calidad del aire, medir y prever la conta- } \\
\text { minación atmosférica, reducir la contaminación } \\
\text { atmosférica de los transportes, disminuir la conta- } \\
\text { minación atmosférica industrial, actuar por la salud } \\
\text { pública }\end{array}$ & $76 \%$ \\
\hline Ruido & $\begin{array}{l}\text { Controlar y atenuar la contaminación sonora; co- } \\
\text { nocer y seguir las cuestiones ligadas al ruido; dismi- } \\
\text { nuir los ruidos sonoros ligados a los desplazamientos; } \\
\text { reducir el ruido causado por los trabajos urbanos }\end{array}$ & $90 \%$ \\
\hline Energía & $\begin{array}{l}\text { Utilizar la energía de manera racional; favorecer una } \\
\text { política de energías renovables; continuar la utiliza- } \\
\text { ción racional de combustibles; hacer una evaluación } \\
\text { regular del consumo de energía de la aglomeración }\end{array}$ & $61 \%$ \\
\hline Riesgos & $\begin{array}{l}\text { Tomar en cuenta los riesgos naturales y tecnológicos; } \\
\text { conocer mejor y prevenir los riesgos geológicos y de } \\
\text { inundación; favorecer la concertación en materia } \\
\text { de riesgos tecnológicos; gestionar mejor el tráfico de } \\
\text { transportes de material peligroso en la aglomeración }\end{array}$ & $81 \%$ \\
\hline $\begin{array}{l}\text { Observa- } \\
\text { torio del } \\
\text { Medio } \\
\text { Ambiente }\end{array}$ & $\begin{array}{l}\text { Desarrollar una herramienta de seguimiento del } \\
\text { medio ambiente; continuar la descripción y segui- } \\
\text { miento de la situación ambiental; integrar el Obser- } \\
\text { vatorio del Gran Lyon en el proceso europeo }\end{array}$ & $71 \%$ \\
\hline $\begin{array}{l}\text { Informa- } \\
\text { ción }\end{array}$ & $\begin{array}{l}\text { Informar, sensibilizar, educar y hacer participar a la } \\
\text { población; conocer mejor los espacios naturales del } \\
\text { Grand Lyon; favorecer una pedagogía del medio } \\
\text { ambiente; crear y hacer vivir los sitios de educación } \\
\text { del medio ambiente; desarrollar la información sobre } \\
\text { el agua y la limpieza }\end{array}$ & $76 \%$ \\
\hline
\end{tabular}

Fuente: Carta Ecológica, 1997-2001. 


\subsection{Efecto de las politicas urbano-ambientales en la comunidad en Lyon}

A partir de los años noventa, las políticas ambientales de la Courly han tenido una importante evolución. La movilización de los actores entre los años 1990 y 1992, y posteriormente en 1996, 1999 y 2000 determinaron buena parte de las políticas. Estos actores llegaron en un primer momento a las arenas de políticas marcadas por una confrontación, en la cual se encuentra el lugar del medio ambiente en la planificación de la ciudad. Entre 1990 y 1991, el proyecto director urbano de la aglomeración lyonesa fue cuestionado por miembros del partido ecologista, razón por la cual no se pudo poner en marcha. Ello obligó a reconsiderar las bases en que descansaba la planificación e introducir nuevos mecanismos de consenso, situación que cambió la forma de concebir las políticas ambientales de la aglomeración lyonesa. La fuerza del desarrollo económico de la región urbana, notable por el peso de su industria, aumenta el número de transformaciones y cambios en los espacios de desarrollo de la ciudad. Ello implica que los temas medioambientales deben adherirse a esta dinámica (Système de Planification de l'Agglomération Lyonnaise, 1995).

La participación ciudadana también fue activa a lo largo de todo el periodo, donde la presencia es más fuerte durante las etapas de gran afluencia política o de ratificación de proyectos (1991, 1992, 1996, 1999 y 2000). Las asociaciones también crecen y continuamente se enfocan a la lógica de la reivindicación de las demandas que van más allá de la competencia de la aglomeración (la contaminación nuclear, los organismos genéticamente modificados), hasta la demanda de disminución en el peaje de carreteras o el estatus de los inmigrantes en la ciudad.

Sin embargo, esta dinámica de participación ciudadana enfocada al medio ambiente ha comenzado a revertirse. Del gran interés establecido por la ciudadanía a inicios de los años noventa, se comienzan a observar ciertas conductas no deseables entre los habitantes. Las cifras marcan una tendencia al alza en la producción de materiales que no se reciclan, así como el declive en la recolección selectiva de los desechos. Parece que las grandes medidas de la política ambiental, sobre todo aquéllas producto de la experiencia y por sus políticas de información, no logran tener los efectos previstos. La movilización de asociaciones es importante, y como lo hemos remarcado, ayudan a promover valores en la protección ambiental o al seguimiento en la implementación de las acciones, pero más allá de las tareas y los datos, se habla de un cierto vacío en el comportamiento ciudadano en relación con los esfuerzos de preservación de su medio. 


\section{Aguascalientes}

\subsection{Diseño de políticas públicas en Aguascalientes}

Durante el periodo, la problemática ambiental se enfocó en tres ejes: la escasez y distribución del agua (Madrid, 1995), el tratamiento de desechos sólidos y, de forma aislada, en la calidad del aire y la educación ambiental (planes municipales de desarrollo, diversos años). En lo fundamental, la agenda se construyó a partir de la iniciativa de los ejecutivos locales, apoyados ocasionalmente en recomendaciones hechas por asociaciones ambientalistas. La planeación urbana es el eje al cual se supeditan las acciones ambientales (Enríquez, 2001; Ortiz, 1997, 2001; Sifuentes, 1994).

El contexto interno de la ciudad repercutió de manera sensible en el diseño de políticas. Primero, la alternancia en el gobierno tuvo efectos en la reconfiguración de las áreas administrativas de corte ambiental: a partir de 1996 las gestiones locales han buscado hacer más eficiente la gestión ambiental, y para ello han desplegado diferentes estrategias relacionadas, en lo fundamental, con una reorganización de las áreas administrativas y de gestión del ambiente de la ciudad (Cabrero y Vega, 1999, planes e informes de la presidencia municipal de Aguascalientes, 1990-2002). Sin embargo, el tema ambiental no tiene una autonomía de planificación puesto que siempre se supedita a la planeación urbana de la ciudad. Esto puede verse reflejado en las diferentes modificaciones de la agencia ambiental de la ciudad que tiene funciones pedagógicas o de salud preventiva, pero que sus alcances rara vez trascienden aspectos como el agua, los desechos sólidos o la contaminación del aire. De igual forma, si bien los estilos de gobierno no son tan marcados en las diversas gestiones locales en la ciudad, la propia lógica de crecimiento urbano de la ciudad ha afectado los discursos, la planificación y sus objetivos, así como la forma de plantear los problemas ambientales. La programación de políticas ambientales se ha hecho a partir de la planificación con un doble enfoque: primero, desde las necesidades de ordenamiento urbano, el medio ambiente se impone como un eje obligatorio pero sin ser estratégico para la ciudad; segundo, desde la perspectiva de los servicios públicos, el agua se ubica como el tema clave. Los planes urbanos 1989-1994, 1994-2000 y 2000-2020 enfocan estrategias e instrumentos en los servicios públicos: recolección y tratamiento de desechos sólidos, agua potable y control de contaminación del aire. A partir de 1994, la ciudad comenzó a integrar procesos Iso-14000 en la elaboración de sus rellenos sanitarios (Presidencia Municipal de Aguascalientes, 1980, 1994, 2000). 


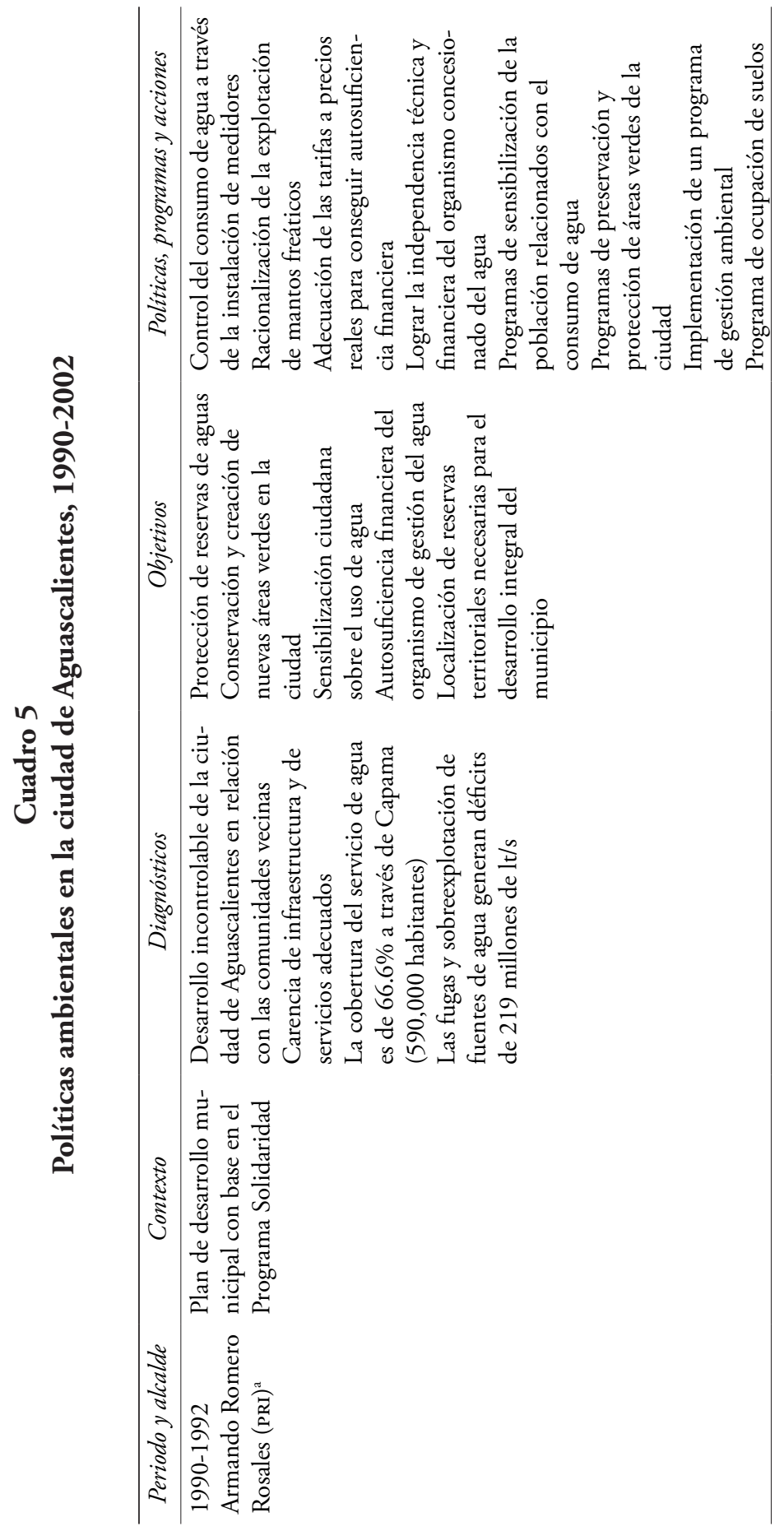




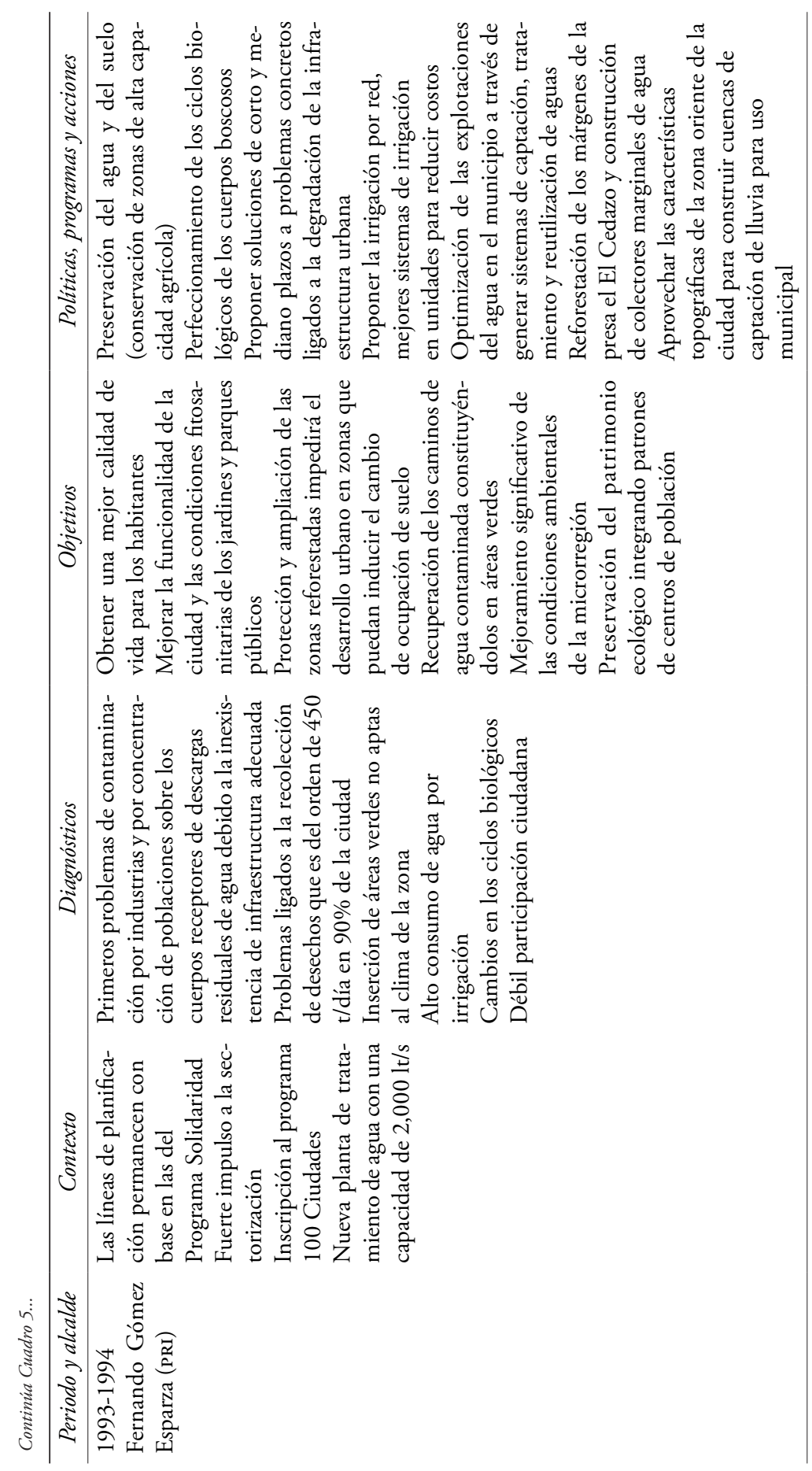




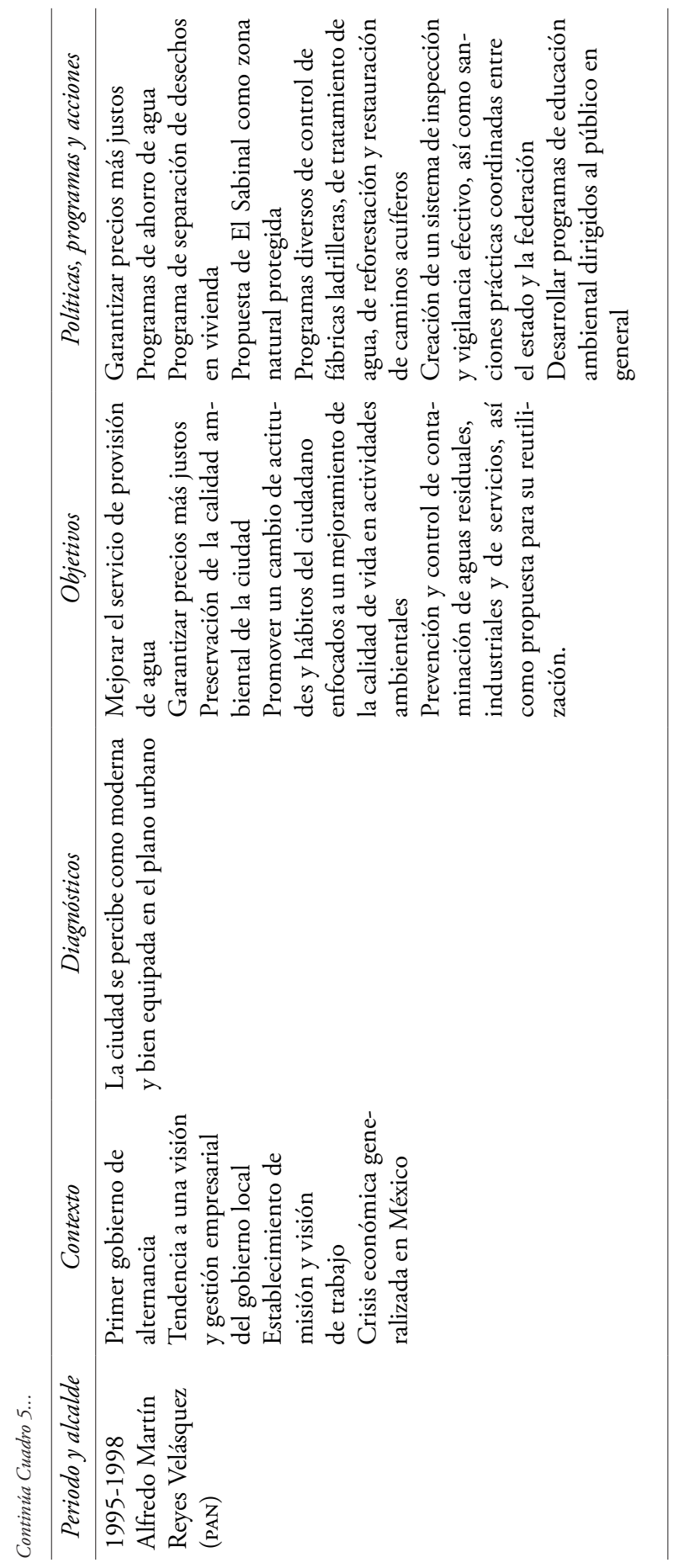




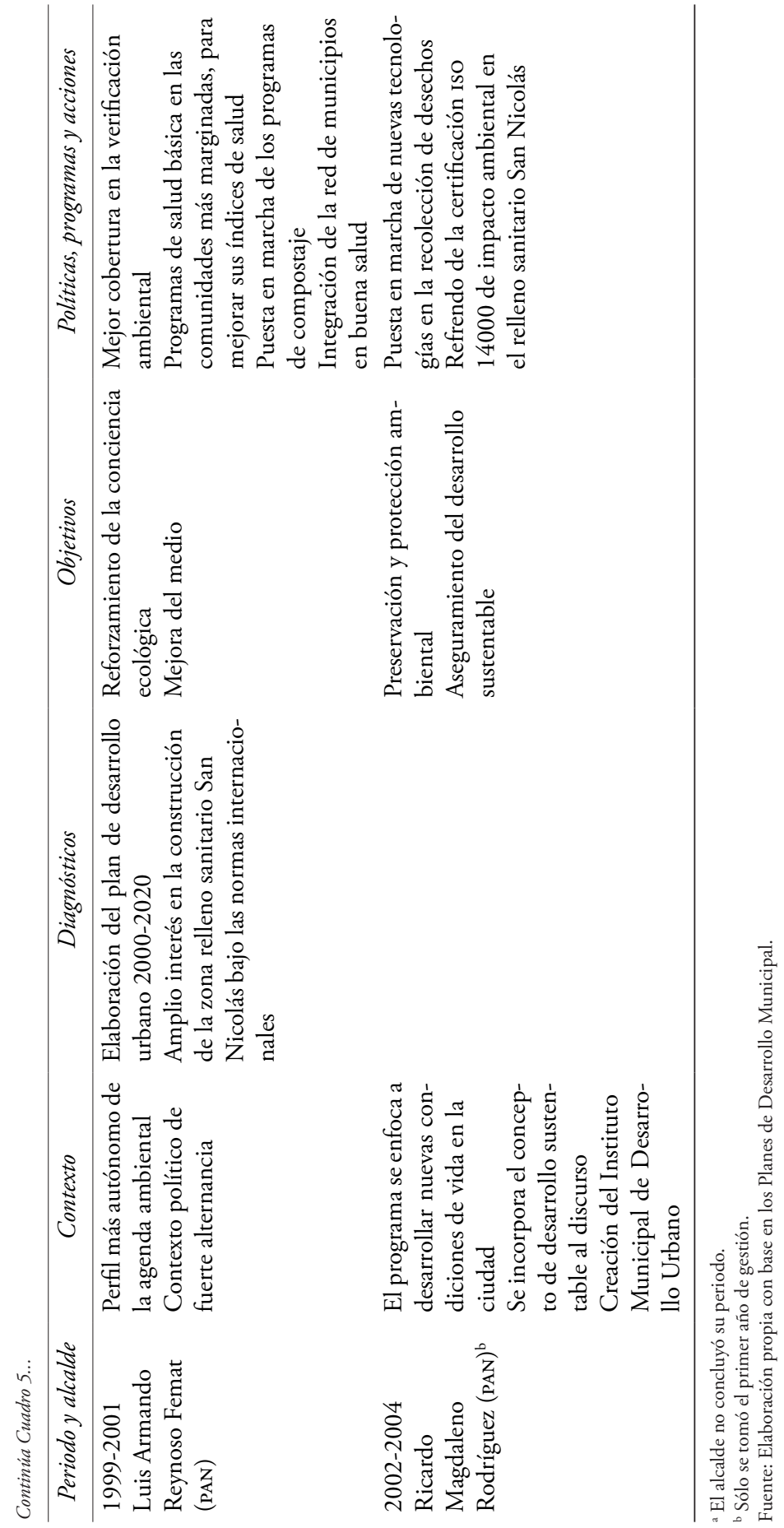




\subsection{Impacto de las políticas urbano-ambientales en la gestión de la ciudad de Aguascalientes}

Las evaluaciones hechas a la planificación urbana de la ciudad indican que hay ciertos objetivos que no han sido aplicados o que, una vez llevado a cabo, no cumplen con las expectativas por las cuales fueron creados. Esta ambigüedad se entiende desde la propia dinámica de la ciudad, donde sus factores internos y externos inciden en el diseño e implementación de las políticas ambientales. Éstos pueden aparecer con mayor o menor intensidad en las arenas de políticas no ambientales, pero que de igual forma afectan el desempeño de la organización y de la gestión ambiental: las restricciones presupuestarias, el perfil de los responsables de las áreas de planificación, la interacción y comportamiento de los ciudadanos, etc. En el caso de la ciudad de Aguascalientes, es sintomático que el trabajo de planeación urbano-ambiental parece que se deteriora paulatinamente, tanto desde el ámbito de la gestión local, que percibe y corrige de forma limitada los problemas, como de la percepción de la población en general, que no observa problemas ambientales importantes o que si los ve, confía en la labor del gobierno para resolverlos. Esta situación parece enfocar la lógica de la planeación ambiental: los viejos problemas ambientales, no resueltos de forma satisfactoria, se suman a los nuevos, con lo que se corre el riesgo de que sean tratados de manera similar en la planeación urbana.

Los desacuerdos parecen surgir en cuanto a la forma de abordar la agenda ambiental de la ciudad. Destaca sin lugar a dudas que algunos miembros de ONG ambientalistas expresen abiertamente que la planeación urbano-ambiental en la ciudad es inexistente. Tal afirmación puede estar apoyada en que: a) si bien existen los programas y objetivos de la planeación urbana de la ciudad, éstos no han sido aplicados ya sea porque existen presiones de parte de intereses privados, o los instrumentos no son adecuados a ciertos contextos particulares; $b$ ) el personal técnico y de apoyo que diseñó los planes no cuenta con la capacitación ni perfil profesional adecuado para hacer frente al tema urbano ambiental en la ciudad, y c) existen intereses personales y de grupos de presión (ya sea económicos, políticos o de la propia sociedad, aunque esta última en menor medida) que intentan modificar la planeación a su favor, aun por encima del marco normativo, lo que repercute en que ciertas aplicaciones de los programas de urbanismo y medio ambiente estén en suspenso o que su aplicación sólo sea parcial, dejando con ello problemas sin resolver.

Finalmente, una de las principales evidencias del efecto de los procesos de implantación Iso 14000 son los rellenos sanitarios de San Nicolás y Cumbres como experiencias exitosas de buen gobierno. Las bases de 
esta experiencia se encontraron en que las estrategias para la implantación de las políticas se centraron en detectar un problema grave, como los rellenos sanitarios. Los resultados han sido no sólo la certificación Iso 9001 de 1998 a la fecha (2008), sino diversos reconocimientos nacionales e internacionales y el que esta experiencia se vea como referente de aprendizaje en América Latina (Sánchez y García, 2008).

\subsection{Efectos de las políticas urbano-ambientales en la comunidad de Aguascalientes}

En el ámbito de la organización ciudadana parece existir una condición de expectativa en la acción de las organizaciones con respecto al medio ambiente. La participación social proambiental es baja. Se perciben conflictos en las relaciones entre algunas ONG y el gobierno. Los actores proambientales organizados se encontraban en medio de tensiones con el gobierno local a causa de lo que consideran una apropiación de la actividad social. Sin embargo, al parecer es precisamente la ausencia de esta actividad social la que obliga al gobierno local a promocionar acciones que confrontan la labor de las asociaciones. Pese a ello, las asociaciones ecológicas de la ciudad de Aguascalientes (Red de Educadores Ambientales, Conciencia Ecológica, Unión de Grupos Ambientales) cumplen, aun de forma restringida, labores de educación ambiental y de protección de ciertas zonas ecológicas. En este caso, también fue evidente la presencia de un ambientalismo militante-político, ya que ciertos líderes optaron por integrarse a agencias ambientales del Estado, con el fin de participar en las decisiones enfocadas a dicho tema. Si bien su presencia era débil, ciertas peticiones, sobre todo las relacionadas con la prevención de riegos en la ciudad, comenzaron a tomarse en cuenta.

Las políticas diseñadas en los años noventa han comenzado a recoger experiencias en planificación sostenible de microterritorios de la ciudad de Aguascalientes, como es el caso del Plan de Ordenamiento del Ejido de Jaltomate, experiencia en la que encontramos aportaciones de la planeación ambiental de la ciudad (Díaz, 2004). De igual forma, se observa una tendencia al uso de la instrucción ciudadana como un eje exitoso en la persuasión, protección y conservación del agua entre los estudiantes (Díaz, 2006).

\section{Principales conclusiones: las cuatro claves de los procesos de transcodificación y de aprendizaje de la acción pública urbano- ambiental}

La evidencia determina la existencia de diferentes resultados de los procesos de aprendizaje interno y externo en ambas ciudades. En los dos 
casos el aprendizaje de las organizaciones tiene efectos en el desarrollo de las políticas ambientales. La capacidad de planificación y programación que se construye de forma autónoma en ambas ciudades, permite tener una constante evaluación y reflexión en los resultados que se obtienen. Si bien los resultados en los dos casos no parecen acercarse al ideal, lo cierto es que su existencia promueve una serie de adecuaciones en la organización de gobierno de estas ciudades.

Hemos logrado aislar los resultados de estos procesos internos y externos de transcodificación y de aprendizaje para nuestros casos. Tres son resultados concretos: la competitividad de la ciudad; la dirección hacia políticas de capital social y el afinamiento del desarrollo económico-urbano de la ciudad. El último contiene elementos de análisis que lo hace complicado de determinar de forma concreta: la adaptación del concepto ambiental en ambas ciudades. La existencia de estos productos se detectó a través de diferentes análisis sobre propuestas iniciales, dinámicas de reflexión de la organización, reconstrucción de las plataformas de conocimiento, planificación y programación de la ciudad y resultados concretos. En el cuadro 6 se muestran las principales variaciones en el diseño de políticas, la gestión ambiental y la dinámica de los actores en cada caso. Su estructura compara tres temas centrales: el territorio, las agencias y las agencias/actores en relación con el diseño e implantación de las políticas públicas. Para el caso del territorio se tomó en cuenta si existe o no ordenamiento o planeación del territorio urbano en ambos casos. En la parte de agencias, se toma en cuenta la modificación de la estructura organizacional, la visión del funcionario hacia el ambiente, el tipo de servicio desarrollado y el diseño, instrumentos y dominio de la política pública implantada en cada ciudad. En cuanto a las agencias/ actores, se tomó en cuenta el tipo de organización ciudadana, los enfoques que ésta tomó como referente y la repercusión que tuvo luego de la ola ambientalista de los ańos noventa.

En la figura I se muestra el proceso y resultados de la transcodificación y aprendizaje derivados de la experiencia de diseño e implementación de las políticas ambientales en la Courly y en Aguascalientes. Podemos decir que el afinamiento de desarrollo urbano y económico enfatiza ejes tecnológicos, de cooperación público-privado y regulación entre las firmas, la sociedad y el gobierno; la competitividad enfocada a mejor infraestructura ambiental; la gobernanza como mecanismo estratégico y de regulación y el capital social, como la generación de aprendizaje y educación ambiental en las ciudades. 


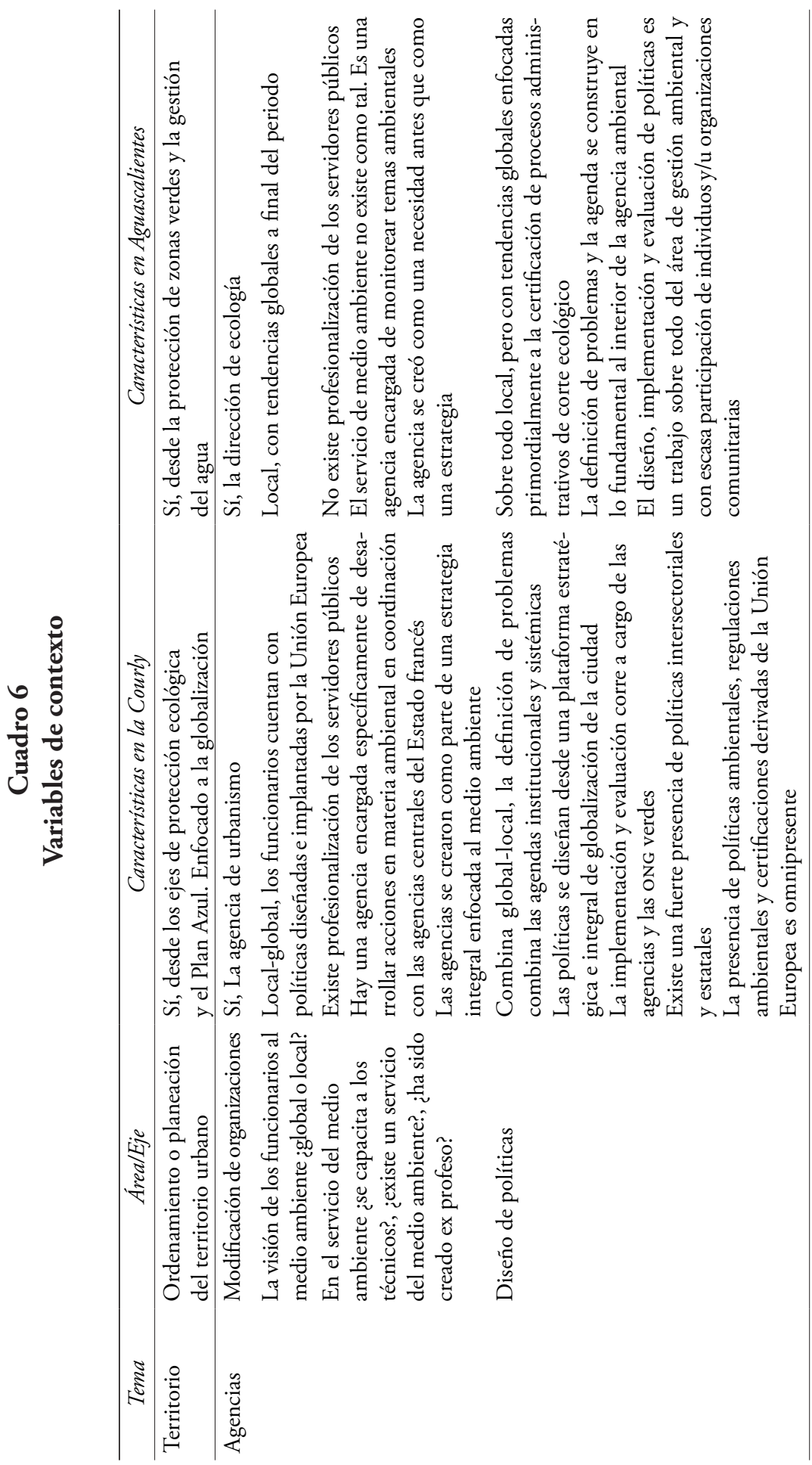




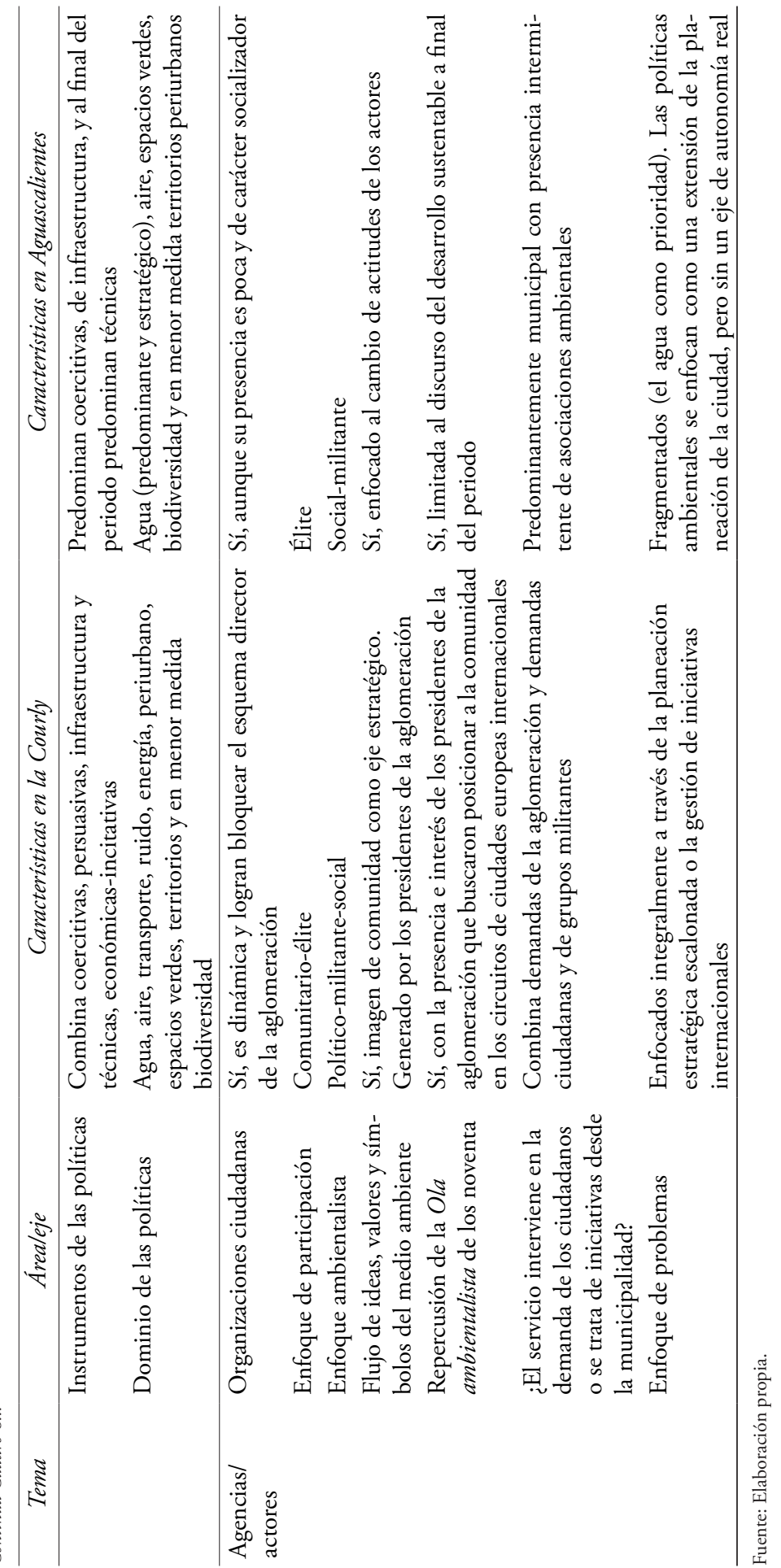




\section{Figura I}

Proceso y resultados de la transcodificación y el aprendizaje urbano ambiental en las ciudades de Aguascalientes y Lyon

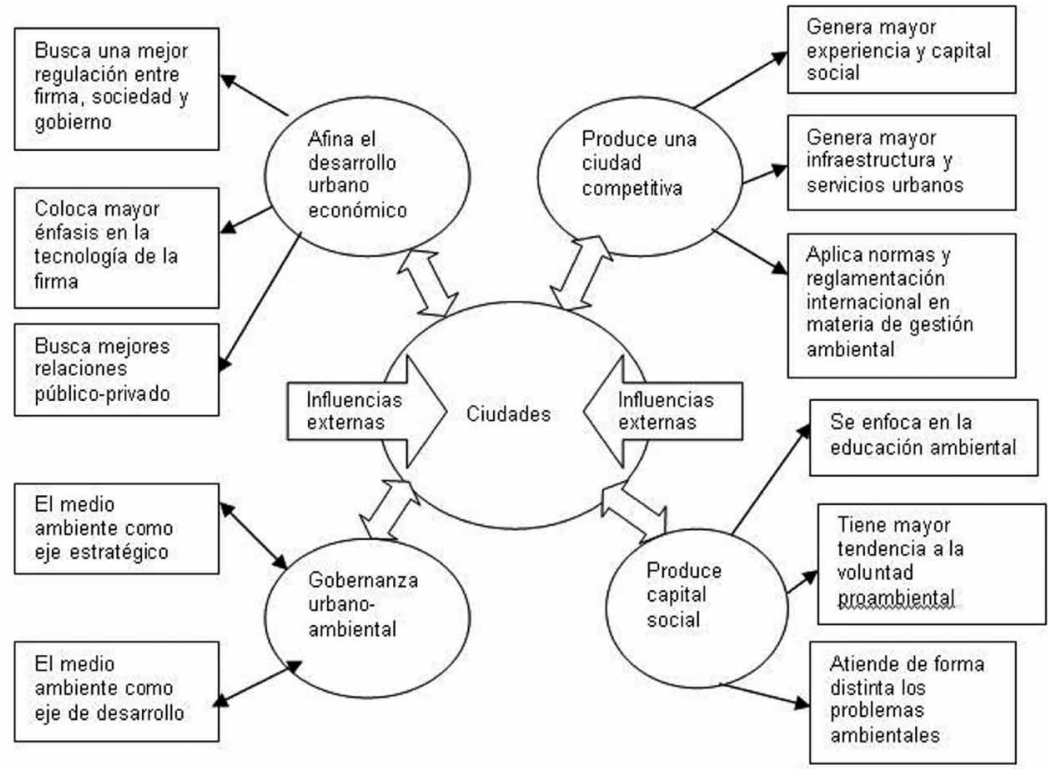

Fuente: Elaboración propia.

\subsection{La acción pública urbano-ambiental que se orienta a una ciudad competitiva}

Uno de los primeros productos de la regulación y organización de intereses entre actores y grupos en ambas ciudades ha sido explotar sus capacidades competitivas en el terreno urbano-ambiental. Parte de éstos determina que la aplicación de normas y ejes ambientales específicos permite a las ciudades convertirse en territorios de competencia urbana tanto interna como externa. En este sentido, la idea de competitividad urbana representa "un proceso fuertemente localizado que fomenta la especialización y la eficacia” (Cabrero et al., 2003: 4). En efecto, la idea de la competitividad urbana permea este proceso de transcodificación para hacerlo operacional. Si bien cada ciudad busca ser eficaz y eficiente a partir de referencias y modelos de políticas distintas, convergen una vez que movilizan de forma estratégica recursos y capital humano en torno al área urbano-ambiental. Por ejemplo, al adoptar la norma internacional y los sistemas de gestión ambiental internacional se busca dinamizar la presencia de las ciudades como ejes de atracción de inversión y como centro de competencia. La ciudad se obliga, de cierta manera, a 
vigilar que la firma que desea instalarse en su territorio sea limpia. Al parecer estos procesos tienen fuerte relación con los contextos de estabilidad política con los que ambas ciudades cuentan. Sin embargo, ello no estuvo exento de consecuencias en ambos casos con el establecimiento de firmas con altos costos ambientales, pero que ofertan empleos, o con la presencia de empresas que no cumplen normas ambientales pero con actividades altamente lucrativas.

Por otro lado, ambas ciudades dedican buena parte del tiempo a generar políticas urbanas que les permiten contar con infraestructura y servicios adecuados para insertarse en esta dinámica competitiva. Ello requiere, también, un mayor conjunto de áreas en las que el medio ambiente se va integrando poco a poco en la agenda y en los procesos de política, cuestión que hace necesario responder de forma más eficiente a los problemas. La manera con la que cuentan estos espacios es precisamente a través de constituirse en redes de actores y grupos (públicos y privados) que se especializan cada vez más en los temas urbano-ambientales, sobre las técnicas que son necesarias de aplicar, y sobre los diferentes estados de la gestión en los que se requiere implementar ideas de desarrollo urbano-ambiental que considere una ciudad competitiva.

\subsection{La acción pública urbano-ambiental orientada a afinar el desarrollo económico}

En nuestros estudios de caso, la categoría urbano-ambiental se ajustó a los patrones de desarrollo económico de las ciudades. Incluir al medio ambiente como tema de interés público permite a los gobiernos contar con un margen de maniobra amplio, pues por un lado se ven obligados a tener una participación más amplia en busca de regular conflictos y, por otro, las empresas tienen la necesidad de acercarse a los funcionarios elegidos, con el fin de establecer las reglas en las emisiones de contaminación. La idea de buscar una cooperación más estrecha entre las empresas ha sido parte fundamental de esta labor. De este modo, a lo largo del periodo en ambos gobiernos se privilegió la cooperación entre empresas, sin embargo, se enfrentó a una serie de problemas: en las dos ciudades la posición entre las empresas y lo local parece no ser una prioridad para las primeras. La propia lógica de la competencia hace que su cooperación se fundamente largamente en una evaluación de su costo-beneficio.

Esta evaluación se observó tanto en Aguascalientes como en la Courly. En la primera, la instalación de empresas con un alto efecto en la explotación de recursos naturales versus la promoción y generación de empleo fueron motivo de conflictos entre el gobierno y los grupos ecologistas. En la segunda, el perfil económico de la comunidad urbana, con un corredor 
de industria química, mecánica y farmacéutica pesada, la hace proclive a grandes riesgos; es ahí donde los esfuerzos sociales, de gobierno y empresas comienzan a coincidir a fin de regular la participación y el mercado de contaminación de las empresas.

\subsection{La acción pública urbano-ambiental orientada a la formación de capital social}

A lo largo del estudio se observan diferentes mutaciones de la identidad e identificación ciudadana en relación con su espacio urbano-ambiental. $\mathrm{Al}$ parecer esto fue un proceso más profundo y evidente en el caso lyones, y más lento en el aguascalentense. Las transformaciones han operado de forma diferente y con lógicas culturales distintas (en el sentido de las imágenes, valores y símbolos que comparten individuos de un mismo grupo social y territorial). Ello determina en gran medida el efecto con el cual el discurso de identidad e identificación es aceptado en la comunidad. Para ambas comunidades, el proceso de identidad de sus ciudadanos se dio a través de la necesidad de adaptación y con la aplicación de nuevas políticas. En este sentido, el medio ambiente ha servido como ese motor de transformación. Como se observó, los responsables políticos echaron mano de diferentes modalidades de promoción de su territorio, en el que se busca resaltar un sentido de pertenencia. El fortalecimiento de esta identidad, se puede inferir, tiene efectos profundos entre los habitantes, que potencialmente tienen mayor interés en protegerlo y preservarlo. Este trabajo ha sido de constante correspondencia entre la sociedad urbana y las autoridades. El rol de las asociaciones en el terreno de los intercambios sociales en Lyon es muy variado. Autores como Pierre Boino afirman que el papel jugado por las asociaciones en la región Rhône-Alpes en términos de una dinámica interna-externa, parte del hecho de que las asociaciones presentes son muy diferentes unas de otras, "pero que tienen en común estar formadas por actores profesionales, económicos y/o políticos" (Boino, 2004: 49). De este modo, los objetivos de las asociaciones son poner en marcha los ejes de intercambio, cooperación y apertura en la región urbana de Lyon, a fin de facilitar una reflexión fuera de los procesos decisorios. Las redes de intercambio, desarrolladas por los diversos grupos y organizaciones "se dan por misión el facilitar la integración de las innovaciones en el sector, esto es, ver un campo social dado. Ellas actúan a la vez como instrumentos de vigilancia tecnológica o social, pero también como vectores que buscan organizar la integración efectiva de una innovación dada en una sector específico" (Boino, 2004: 52-53). En Lyon, el asociacionismo en todos estos ejes se dirige a una lógica de interacción que busca regular el funcionamiento social de la comunidad urbana a través de orientar y vigilar los intercambios sociales. 
Ambos casos han utilizado el mecanismo de la promoción de la ciudad como parte del proceso de transformación de la identidad. Las ciudades se invisten de este modo, de capacidades dinámicas, modernas y adaptadas al contexto que las rodea o, dicho de otra forma, respetuosas de su entorno. El entramado social, en este caso, se va modificando para adoptar, o rechazar, el modelo de ciudad que se propone; es ahí donde las asociaciones juegan un papel más activo. En efecto, es necesario recordar que las políticas urbano-ambientales serían efectivas sin la presencia de las asociaciones, pero en todo caso no serían las mismas sin su presencia (Lascoumes, 1994).

\subsection{La acción pública urbano-ambiental orientada al cambio del concepto urbano ambiental}

Queda finalmente el punto en el cual se cruzan los tres productos de los procesos de transcodificación y de aprendizaje desarrollados en la ciudad de Aguascalientes y en la Comunidad Urbana de Lyon. Este último punto, sin embargo, ha sido difícil de interpretar dado que su mutación, a lo largo del periodo, parece ser no sólo lenta sino portadora de diferentes significados, dependiendo de las características de la ciudad: se trata, pues, de una redefinición del medio ambiente. En efecto, conforme las ciudades han ido evolucionando de una ciudad de oportunidades y con infraestructura y servicios urbanos adecuados, hacia otra de ambiciones, más gerencialista y competitiva, el medio ambiente urbano ha tenido que ser aislado e insertado en la base de estos cambios. Ajustar el concepto medio ambiente a esta idea de ciudad, como hemos visto, incluye no sólo a actores y grupos, sino que representa procesos de interpretación y adaptación de discursos y acciones. El cambio en el concepto urbano ambiental tiene, por un lado, una lógica estratégica global y de alta competitividad, que son atributos de una ciudad moderna. Esta imagen se compartió de forma amplia en la Comunidad Urbana de Lyon y progresivamente en Aguascalientes. El medio ambiente urbano, sobre la base de este modelo de ciudad, se convierte en un instrumento de legitimación de las acciones y punta de lanza de la programación y planificación de la ciudad. Los actores y grupos proambientales se movilizan alrededor de ello y, finalmente, como lo explicamos, el rechazo del modelo no es, de hecho, hacia el contenido, sino a la forma en que éste se desarrolla.

\section{Bibliografía}

Aguilar, Miguel Ángel (2002), "Indentity and daily space in two municipalities in Mexico City", Environnement and Behaviour, 34 (1), Sage, Thousand Oaks, pp. 111-121. 
Arellano Gault, David (2006), Los dilemas de la gestión local y las organizaciones comunitarias en México, Centro de Investigación y Docencia Económicas, México.

Arnaud, Emmanuel, Arnaud Berger y Christian de Perthuis (2005), Le Développement Durable, Série Repères Pratiques, Nathan, Francia.

Barker, Anthony y B. Guy Peters (eds.) (1993), The politics of expert advice. Creating, using and manipulating scientific knowledge for public policy, Edimburg University Press, Edimburgo.

Barraqué, Bernard y Jacques Theys (dirs.) (1998), Les politiques de l'environnement. Évaluation de la première génération: 1971-1995, Recherches, París.

Besse, Juan (2000), "Los dilemas de Jano. El rol, la posición y la disposición del investigador en la práctica de evaluación de impacto de políticas a través de métodos y técnicas cualitativas", Gestión y Politica Pública, Ix (1), Centro de Investigación y Docencia Económicas, México, pp. 5-38.

Boino, Paul (2004), "Les associations: dispositif organisationnel de la métropolisation", en Les Cahiers Millénaire, 3, Grand Lyon, pp. 49-53.

Bonneville, Marc (1997), Lyon, Métropole Régionale ou Euro-cité?, Anthropos, París.

Borraz, Olivier (1999), "Pour une sociologie des dynamiques de l'action publique locale", en Richard Balme et al., Les Nouvelles Politiques Locales, Presses de Sciences Po, París, pp. 77-110.

Borraz, Olivier (2000), "Le gouvernement municipal en France. Un modèle d'intégration en recomposition", Pôle Sud, 13, Climats, Montpellier, pp. 11-26.

Brown, David S., Christopher J. Brown y W. Scott Desposato (2008), "Who gives, who receives and who wins? Transforming Social Capital into Political change through Non-governmental Organizations", Comparative Political Studies, 41 (1), Sage, Thousand Oaks, pp. 24-47. 
Cabrero, Enrique y Alejandro Vega (1999), El municipio de Aguascalientes (1988-1998). ¿Estabilidad en la alternancia?, Centro de Investigación y Docencia Económicas, México.

Cabrero, Enrique, Isela Orihuela y Alicia Ziccardi (2003), Ciudades competitivas-ciudades cooperativas: conceptos claves y construcción de un indice para ciudades mexicanas, Centro de Investigación y Docencia Económicas, México.

Cabrero-Mendoza, Enrique (2005), Acción pública y desarrollo local, Fondo de Cultura Económica, México.

Caldwell, Linton Kaldwell (1995), Environment as a focus for public policy, Texas A\&M Press, Texas.

Charte de l'Écologie Urbaine du Grand Lyon (1992), Plan d'action 19921995, Communauté Urbaine de Lyon, Lyon.

Charte de l'Écologie Urbaine, Agenda 21 (2000a), Agir pour l'environnement, Plan d'action 1997-2001, Communauté Urbaine de Lyon, Lyon.

Charte de l'Écologie Urbaine, Agenda 21 (2000b), État d'avancement 2000, Communauté Urbaine de Lyon-Observatoire de l'Environnement, Lyon.

Cheremisinoff, Nicholas (2001), Handbook of pollution prevention practices, Marcel Dekker, Nueva York.

Comission Europeene (1994), Ville et environnement, Comunidad Europea, Bruselas-Luxemburgo.

Corral-Verdugo, Víctor (2002), "A structural model of pro-environmental competency", Environment and Behavior, 34 (4), Sage, Thousand Oaks, pp. 531-549.

Corwell, Stephen, Mark Deakin y Martin Symes (2005), Sustainable Urban Development, Routledge, Londres.

Díaz-Flores, Manuel (2004), "Plan de ordenamiento de la reserva del ejido de Jaltomate en Aguascalientes, Aguascalientes", en Rodolfo García del Castillo, Gestión local creativa: experiencias innovadoras en México. Premio Gobierno y Gestión Local, Centro de Inves- 
tigación y Docencia Económicas-Instituto Nacional para el Federalismo y el Desarrollo Municipal-Fundación Ford, México, pp. 243-254.

Díaz-Flores, Manuel (2006), "Cultura del agua en las escuelas, Aguascalientes, Aguascalientes", en Tonatiuh Guillén, Pilar López y Pablo Rojo (coords.), Municipio y buen gobierno: experiencias del impetu local en México. Premio Gobierno y Gestión Local, Centro de Investigación y Docencia Económicas, México, pp. 222-233.

Dolowitz, David y David Marsh (2000), "Learning from Abroad: The Role of Policy Transfer in Contemporary Policy-Making", Governance: An International Journal of Policy and Administration, 13 (1), New Jersey, pp. 5-24.

Duran, Patrice (1999), Penser l'Action Publique, Lgdj, París.

Ecologie urbaine. Tableau de bord, analyse (1996), Communauté Urbaine de Lyon-Observatoire de l'Environnement, Lyon.

Enríquez-Aranda, Rogelio (2001), "Historia de la urbanización en Aguascalientes (1810-1985)", en José Antonio Ortiz-Garza (comp.), Sociedady Desarrollo Urbano en Aguascalientes, 59 (6), Universidad Autónoma de Aguascalientes, México, pp. 509-522.

Epstein, Barbara (2000), "Grassrots environmentalism and strategies for social change", Documento New Social Movement Network, Londres.

Falque, Max (1992), "Gestion Patrimoniale et nouvelle économie de l'environnement", Politiques et Management Publique, 10 (1), MSH, París, pp. 111-143.

Font, Joan (2001), Ciudadanos y decisiones públicas, Ariel, Barcelona.

Gunderson, William (1993), "Partisan politics, economic growth, and the roots of NIMBY: the case of Montpellier, France", en John Martin-Gillroy (ed.), Environmental risk, environmental values and political choices, Westview Press, Colorado, pp. 113-127.

Herrick, James (1995), "Empowerment practice and social change: the place for new social movement theory", ponencia presentada en 
New Social Movement and Community Organization, 1-3 de noviembre, University of Washington, Seattle.

Hodos, Jerome (2002), "Globalization, regionalism and urban restructuring. The case of Philadelphia", Urban Affairs Review, 37 (3), Sage, Thousand Oaks, pp. 358-379.

Imber, Mark (1994), Environment, Security and UN Reform, McMillan, Nueva York.

Jiménez-Domínguez, Bernardo y Rosa María López-Aguilar (2002), "Identity and sustainability in two neigborhoods of Guadalajara, Mexico", Environment and Behavior, 34 (1), Sage, Thousand Oaks, pp. 97-110.

Jouve, Bernard (1998), "Planification territoriale, dynamique métropolitaine et innovation institutionnelle: la Région urbaine de Lyon", Revue Politique et Management Publique, 16, мsн, París, pp. 61-82.

Kettl, Donald (2000), "The transformation of governance: globalization, devolution and the role of government", Public Administration Review, 60 (6), Wiley, New Jersey, pp. 488-497.

Khan Jr., Peter y Orlando Lourenço (2002), "Water, air, fire, and earth a Developmental Study in Portugal of Environmental Moral Reasoning", Environment and Behavior, 34 (4), Sage, Thousand Oaks, pp. 405-430.

Larrue, Corinne (2000), Analyser les politiques publiques de l'environnement, L'Harmattan, París.

Lascoumes, Pierre (1994), L'eco-pouvoir, LGDJ, París.

Lascoumes, Pierre y Jean Pierre Le Bourhis (1997), L'environnement et l'administration des possibles. Les DIREN à l'œuvre, L'Harmattan, París.

Leff, Enrique (coord.) (1990), Medio ambiente y desarrollo en México, 2 vols., Universidad Nacional Autónoma de México-Miguel Ángel Porrúa, México.

LeRoux, Kelly (2007), "Nonprofits as civic intermediaries. The role of community-based organizations in promoting political partici- 
pation", Urban Affairs Review, 42 (3), Sage, Thousand Oaks, pp. 410-422.

Linder, Stephen H. y B. Guy Peters (1993), "Instrumentos de gobierno: percepciones y contextos", Gestión y Politica Pública, II (1), Centro de Investigación y Docencia Económicas, México, pp. 5-34.

Mabileau, Albert (1993), Le système local en France, Montchrestien, París.

Madrid-Alanís, Adolfo (1995), Manantiales siglo XVI-XX. Vida y desarrollo. Evolución de los sistemas de agua potable y alcantarillado de la ciudad de Aguascalientes, Presidencia Municipal de AguascalientesCAPAMA, México.

Marie, Jean-Louis (1999), "La réception des politiques publiques par les administrés: une approche cognitive", en Richard Balme, Albert Mabileau, Alain Faure, Les Nouvelles Politiques Locales, Presses de Sciences-Po, París, pp. 447-464.

Martínez-Omaña, María Concepción (1994), Aguascalientes: un ensayo de descentralización (1982-1988), Instituto Cultural de Aguascalientes-Instituto Mora, México.

Melé, Patrice (2001), "Introducción: medio ambiente, orden jurídico y gestión urbana”, en Mario Bassols y Patrice Melé (coords.), Medio ambiente, ciudad y orden jurídico, Universidad Autónoma Metropolitana-Miguel Ángel Porrúa, México, pp. 11-51.

Muller, Pierre e Yves Surel (1998), L'analyse des politiques publiques, Montchrestien, París.

Ortiz-Garza, José Alfredo (1997), Ordenamiento del territorio y desarrollo municipal en Aguascalientes, México, Universidad Autónoma de Aguascalientes, México.

Ortiz-Garza, José Alfredo (2001), "Metropolización en la ciudad de Aguascalientes", en José Alfredo Ortiz-Garza (comp.), Sociedad y desarrollo urbano en Aguascalientes, Universidad Autónoma de Aguascalientes, México. 
Pinson, Gilles y Antoine Vione (2000), "L'internationalisation de la Ville comme objet d'expertise", Pôle Sud, 13, Climats, Montpellier, pp. 85-102.

Presidencia Municipal de Aguascalientes (1980), Programa de desarrollo urbano de la ciudad de Aguascalientes 1980-1994, Aguascalientes, México.

Presidencia Municipal de Aguascalientes (1994), Programa de desarrollo urbano de la ciudad de Aguascalientes 1994-2010, Aguascalientes, México.

Presidencia Municipal de Aguascalientes (2000), Programa de desarrollo urbano de la ciudad de Aguascalientes 2000-2020, Aguascalientes, México.

Sainteny, Guillaume (1998), "Emergence d'un nouvel enjeu de politique publique: le pouvoir face à l'environnement", Politiques et Management Publique, 16 (2), MsH, París, pp. 129-158.

Sánchez-Bernal, Antonio y María Luisa García-Batiz (2008), "Captura y aprovechamiento del biogás de los rellenos sanitarios San Nicolás y Las Cumbres del municipio de Aguascalientes", en Socorro Arzaluz et al. (coord.), Gobierno local efectivo. Experiencias concretas del ámbito local mexicano, Centro de Investigación y Docencia Económicas-Secretaría de Gobernación-Colegio de la Frontera, México, pp. 175-186.

Sifuentes, Mario Alejandro (1994), Aguascalientes: sociedad y urbanismo, Instituto Cultural de Aguascalientes, México.

Stewart, John (2001), "De la innovación democrática a la democracia deliberativa”, en Joan Font (coord.), Ciudadanos y decisiones públicas, Ariel, Barcelona, pp. 77-94.

Système de Planification de l'Agglomération Lyonnaise (1995), Schéma directeur de l'agglomération lyonnaise "Lyon 2010", informe mayo 1992, Agence d'Urbanisme, Lyon.

Uzell, David y Erick Pol (2002), "Place identification, social cohesion and environmental sustainability", Environment and Behaviour, 34 (1), Sage, Thousand Oaks, pp. 26-53. 
Yin, Robert K. (1994), Case study research. Design and Methods, Sage, Thousand Oaks.

Recibido: 18 de mayo de 2010. Reenviado: 14 de octubre de 2010. Aceptado: 27 de enero de 2011.

Carlos Gil-García. Es doctor en estudios latinoamericanos por la universidad París III Nueva Soborna. Actualmente es profesor-investigador del Instituto Tecnológico y de Estudios Superiores de Monterrey, Campus Hidalgo. Sus líneas de investigación son: políticas públicas, medio ambiente, ciudades. Entre sus publicaciones sobresalen: en coautoría, "La agenda de políticas públicas en ciudades mexicanas durante el siglo xx. ¿Cien años de soledad municipal?", Estudios Urbanos y Demográficos, 25 (73, 1), El Colegio de México, México, pp. 133-173 (2010); "Problemas, territorios y organizaciones en la acción pública: los dilemas de la decisión en el caso del nuevo aeropuerto de la ciudad de México", en Juan Labastida Martín del Campo et al., La democracia en perspectiva: análisis y evaluación de las democracias en México, Universidad Nacional Autónoma de México, México, pp. 307-336 (2008). 